\title{
Mixed Convective Conditions on Natural Convection of MHD Blasius and Sakiadis Flows with Variable Properties and Nonlinear Chemical Reaction
}

Chekolu Murali Krishna ${ }^{1}$, Gottam Viswanatha Reddy ${ }^{1}$, Suresh Babu Ramakrishna ${ }^{2}$, Sadanandya Upadhya Mamatha ${ }^{3}$, Chakravarthula Siva Krishnam Raju ${ }^{4, *}$ (D)

1 Department of Mathematics, Sri Venkateswara University, Tirupati-517502, A.P, India; muralich16@gmail.com (C.M.K.); gvr.svu@gmail.com (G.V.R.);

2 Department of Mathematics, M.S. Ramaiah Institute of Technology, Bengaluru-560054, India; sureshbabur@msrit.edu (S.B.R.);

3 Department of Mathematics, Kristu Jayanti College (Autonomous), Bengaluru, India; mamathasupadhya@gmail.com (U.M.);

4 Department of Mathematics, GITAM School of Technology, Bangalore-561203, Karnataka, India; sivapdf90@ gmail.com (C.S.K.R.);

* Correspondence: rchakrav@gitam.edu, sivaphd90@gmail.com;

Received: 16.07.2020; Revised: 16.08.2020; Accepted: 17.08.2020; Published: 21.08.2020

\begin{abstract}
An unsteady two-dimensional boundary layer slip flow of a viscous incompressible fluid moving plate in a quiescent fluid (Sakiadis flow) and the flow-induced over a stationary flat plate by a uniform free stream (Blasius flow) are investigated simultaneously, from a numerical point of view. The variable thermal conductivity, viscosity ratio parameter, and nonlinear chemical reaction are used in the governing equations. Similarity equations of the governing transport equations are converted into an ordinary differential equation. The transformed equations are solved numerically using the Runge-Kutta method via the shooting technique. Sample results for the dimensionless velocity, temperature, and concentration distributions are studied through graphically. Moreover, friction factor, heat, and mass transfer rates have been discussed in detail. The chemical reaction parameter decelerates the friction factor and heat transfer rates for the Sakiadis and Blasius flow cases and enhances in mass transfer rate in both cases. The rate of mass transfer is higher in Blasius flow compared with Sakiadis flow. The present results of the heat transfer rate are compared with the published results are found to be in good agreement.
\end{abstract}

Keywords: Viscous ratio parameter; variable thermal conductivity parameter; Blasius and Sakiadis flows; chemical reaction parameter.

(C) 2020 by the authors. This article is an open-access article distributed under the terms and conditions of the Creative Commons Attribution (CC BY) license (https://creativecommons.org/licenses/by/4.0/).

\section{Introduction}

The fluid flows across a surface or sheet has numerous applications and usages in various branches of science, technology, and industry. Therefore, there is a significance to enhance the investigation of this kind of fluid flows with different conditions. The concept of fluid flow over a horizontal stationary plate under constant velocity is firstly presented by Blasius [1]in 1908. Later on, Sakiadis [2] proposed a similar problem, but the plate moved with some constant velocity.

In Blasius and Sakiadis flows, the heat transfer analysis occupies a major part. The investigation of electrically conducting fluids over the Sakiadis and Blasius flow cases plays a 
crucial role in various sectors like glass painting, food processing, and automobiles. Hence the following investigations are focused on different types of heat transfer conditions. By viewing the above importance, Pop and Watanabe [3] investigated the heat transfer characteristics of a continuous surface with a suction velocity at the boundary. Recently, Krishna et al. [4] found that the thermal buoyancy parameter enhances the velocity and depreciates the temperature field in both Blasius and Sakiadis flow. Further, Mabood and Khan [5] observed that improvement in radiation and accretion/ablation at leading-edge increases the fluid temperature resulting in the improvement in the thermal boundary layer in both Blasius and Sakiadis flow. The thermal boundary layer(TBL) thickness improved for cylindrical nanoparticles and declined for spherical nanoparticles in both no-slip and slipcases of Blasius, and Sakiadis flows are analyzed by Ganesh et al.[6]. Later, Two-dimensional(2-D) magnetohydrodynamic Blasius and Sakiadis flow considering thermal and diffusion slips with variable fluid properties into account are examined by Krishna et al. [7]. Blasius flow of a nanofluid in the presence of heterogeneous-homogeneous chemical reactions and found that nanofluid significantly participates in the transport mechanism was discussed by $\mathrm{Xu}$ [8]. Second law analysis of classical Blasius flow accounting the effects of nonlinear radiation and frictional heating led to the observation that entropy generation is an increasing function of Prandtl number, heating parameter, Eckert number, and radiation parameter is performed by Afridi and Qasim [9]. An unsteady magnetohydrodynamic (MHD) Blasius and Sakiadis flow by incorporating variable thermal conductivity, viscous dissipation, and thermal radiation was studied by Shateyi and Muzara [10]. The interest in the boundary layer Blasius and Sakiadis flows has grown during the past few decades because of their numerous technological applications, as mentioned above, and several interesting results can be found in [11-15].

Of late researchers have concluded that the exploitation of passive methods in electronic devices, chemical reactors, biomedical industry, food processing, engineering, science, and technology, etc. is most effective in upgrading heat and mass transfer rates in natural convection applications and devices. One of these passive methods is to enforce nanofluids in place of traditional fluids. The amalgamation of metallic particles in traditional fluids is well known as nanofluid. Recently, Sajid et al. [16] took up the experimental investigation of $\mathrm{TiO}_{2}-$ water nanofluid flow and heat transfer inside the wavy mini-channel. A nonlinear thermal convection nanofluid flow over a radiated porous disk was analyzed by Upadhya et al.[17] The preparation of curcumin-loaded PLGA (Nanofluid) nanoparticles and its influence on human glioblastoma U87MG cells was investigated by Arzani et al. [18].Later on, Synthesized cerium oxide nanoparticles using a very simple and green method and demonstrated dye degradation in a short time, is experimentally studied by Shojaee et al. [19]. Activated carbon for the removal of silver nanoparticles from the environment is proposed by Suhartono and Syafiuddin [20].

The effect of thermal radiation on convective heat and mass transfer problems have been studied by numerous researchers owing to its applications in physics and engineering. The radiation effects play a vital role in the cooling of nuclear reactors, polymer processing industry, high-temperature plasmas, power generation systems, liquid metal fluids, magnetohydrodynamic accelerators, etc. The influence of radiation is essential when there is a large dissimilarity in the surface along with the ambient temperature. Recently, Upadhya et al. [21] investigated Jeffrey nanofluid flow over an electromagnetic sheet by considering nonlinear convection, radiation, and Arrhenius activation energy. The influence of radiation on MHD(Magnetohydrodynamic) nanofluid flow employing a two-phase model is discussed by 
Sheikholeslami et al. [22]. Rashid et al. [24] discussed the entropy generation in ferromagnetic fluid flow with slip and nonlinear thermal radiation]. The influence of radiation on thin nanofluid film flow with non-uniform heat source/sink was considered by Pal et al. [24]. Later on, The impact of the eddy viscosity turbulence models by considering convection-radiation in the indoor environment illustrated by $\mathrm{Li}$ and $\mathrm{Tu}[25]$.

By the inspiration of the above studies, the objective of the present study is to find the mixed convective conditions on natural convection of hydromagnetic Blasius and Sakiadis flows with variable properties and nonlinear chemical reactions. The set of governing equations is evaluated and presented with graphs and tables.

\section{Materials and Methods}

\subsection{Mathematical formulation.}

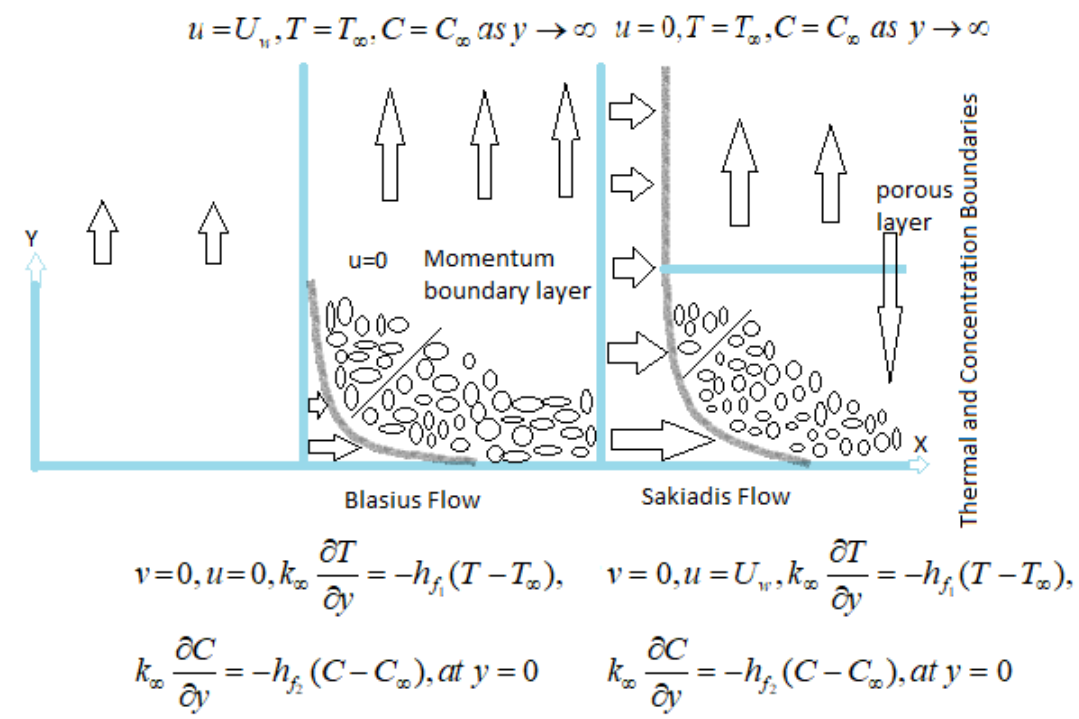

Figure 1. The physical model of the flow configuration.

The unsteady natural convection of Blasius and Sakiadis magnetohydrodynamic flows with variable properties and nonlinear chemical reaction is considered. To control thermal and concentration boundary layers, we also considered the combined effect of Brownian motion and thermophoresis as well as viscous dissipation and thermal radiation with mixed convective conditions (thermal and concentration). It coincides with (Figure 1). The Cartesian coordinate system has its origin located at the leading edge with the positive $\mathrm{x}$-axis extending along with the sheet in the upwards direction, while the y-axis is measured normal to the flow. The unsteady fluid heat flows start at $\mathrm{t}=0$; the sheet is being stretched with the velocity along the $\mathrm{x}$-axis, by keeping the origin is fixed. The thermophysical properties of the sheet or plate and the ambient fluid are assumed to be constant except density variations and the thermal conductivity, which are assumed to vary linearly with temperature. These assumptions (with the Bossiness' and boundary layer approximations), the governing equations for the convective flow and heat transfer of the viscous fluid are $[7,11,15]$ :

$$
\begin{aligned}
& \frac{\partial u}{\partial x}+\frac{\partial v}{\partial y}=0 \\
& \frac{\partial u}{\partial t}+u \frac{\partial u}{\partial x}+v \frac{\partial u}{\partial y}=\frac{1}{\rho} \frac{\partial}{\partial y}\left(\mu_{f} \frac{\partial u}{\partial y}\right)+g\left(\beta_{c}\left(C-C_{\infty}\right)+\beta_{T}\left(T-T_{\infty}\right)\right)-\frac{\sigma B_{0}^{2}}{\rho} u-\frac{\vartheta}{K_{0}} u
\end{aligned}
$$




$$
\rho C_{p}\left(\frac{\partial T}{\partial t}+u \frac{\partial T}{\partial x}+v \frac{\partial T}{\partial y}\right)=\frac{\partial}{\partial y}\left(K(T) \frac{\partial T}{\partial y}\right)+\mu_{f}\left(\frac{\partial u}{\partial y}\right)^{2}+\tau\left(\begin{array}{c}
D_{B} \frac{\partial T}{\partial y} \frac{\partial C}{\partial y} \\
+\frac{D_{T}}{T_{\infty}}\left(\frac{\partial T}{\partial y}\right)^{2}
\end{array}\right)+\frac{16 \sigma^{*} T_{\infty}^{3} \frac{\partial^{2} T}{\partial k^{2}}}{3 y^{2}}
$$$$
\frac{\partial C}{\partial t}+u \frac{\partial C}{\partial x}+v \frac{\partial C}{\partial y}=D_{B} \frac{\partial^{2} C}{\partial y^{2}}-k_{0}\left(C-C_{\infty}\right)^{n}+\frac{D_{T}}{T_{\infty}} \frac{\partial^{2} T}{\partial y^{2}}
$$

subjected to the boundary conditions:

i)

Blasius problem

$$
\begin{aligned}
& v=0, u=0, k_{\infty} \frac{\partial T}{\partial y}=-h_{f_{1}}\left(T-T_{\infty}\right), k_{\infty} \frac{\partial C}{\partial y}=-h_{f_{2}}\left(C-C_{\infty}\right), \text { at } y=0, \\
& u=U_{w}, T=T_{\infty}, C=C_{\infty} \text { as } y \rightarrow \infty \text { as } y \rightarrow \infty
\end{aligned}
$$

ii) Sakiadis problem

$$
\left.\begin{array}{l}
v=0, u=U_{w}, k_{\infty} \frac{\partial T}{\partial y}=-h_{f_{1}}\left(T-T_{\infty}\right), k_{\infty} \frac{\partial C}{\partial y}=-h_{f_{2}}\left(C-C_{\infty}\right), \text { at } y=0, \\
u=0, T=T_{\infty}, C=C_{\infty} \text { as } y \rightarrow \infty
\end{array}\right\}
$$

Here $u$ and $v$ are the velocity components in the $x$ and $y$ directions, respectively, $v$ is the kinematic viscosity, $g$ is the acceleration due to gravity, $\beta_{T}, \beta_{C}$ is the coefficient of thermal and concentration expansions is the fluid temperature, $T_{\infty}, C_{\infty}$ is the ambient temperature and concentration, $\rho$ is the density, $c_{p}$ is the specific heat at constant pressure, $K(T)$ is the variable thermal conductivity, $k_{n}$ is the chemical reaction rate, $\sigma^{*}$ is the Boltzmann constant, $k^{*}$ is Stefan constant, $h_{f_{1}}, h_{f_{2}}$ are the heat transfer coefficients due to thermal and mass. In this paper, the thermal conductivity and viscosity are assumed to vary linearly with temperature as:

$$
\begin{aligned}
K(T) & =K_{\infty}\left(1+\frac{\varepsilon}{\Delta T}\left(T-T_{\infty}\right)\right) \\
\mu_{f}(T) & =\frac{\mu_{\infty}}{\left(1+\omega\left(T-T_{\infty}\right)\right)}
\end{aligned}
$$

Here $\Delta T=\left(T_{w}-T_{\infty}\right), T_{w}$ is the surface temperature, $\varepsilon$ and $\omega$ are small parameters known as the conductivity and viscosity variation parameters, $k_{\infty}, \mu_{\infty}$ are the thermal conductivity and viscosity of the fluid far away from the surface. These particular forms of a $U_{w}(x, t)$ and $T_{w}(x, t)$ have been chosen in order to obtain a new similarity transformation, which transforms the governing partial differential equations (2)-(4) into a set of coupled ordinary differential equations. Defining the following dimensionless functions $f$ and $\theta$, and the similarity variable $\zeta$ as

$$
\zeta=\left(\frac{a}{v(1-c t)}\right)^{\frac{1}{2}} y, \quad \psi=\left(\frac{v a}{(1-c t)}\right)^{\frac{1}{2}} x f(\zeta), \theta(\zeta)=\frac{\left(T-T_{\infty}\right)}{\left(T_{w}-T_{\infty}\right)}, \phi(\zeta)=\frac{\left(C-C_{\infty}\right)}{\left(C_{w}-C_{\infty}\right)}
$$

where, $\psi(x, y, t)$ is a stream function defined as $(u, v)=\left(\frac{\partial \psi}{\partial y},-\frac{\partial \psi}{\partial x}\right)$. By substituting Equations (2)-(4) and making use of Eqs. (7), (8) and (9) we obtain

$$
\frac{1}{(1+E \theta)} f^{\prime \prime \prime}-\frac{E}{(1+E \theta)^{2}} \theta^{\prime} f^{\prime \prime}+f f^{\prime \prime}-f^{\prime 2}-A\left(f^{\prime}+\frac{1}{2} \varsigma f^{\prime \prime}\right)+\lambda_{T} \theta+\lambda_{c} \phi-(M+K) f^{\prime}=0
$$




$$
\begin{aligned}
& \frac{A}{2} \varsigma \theta^{\prime}-f \theta^{\prime}-\frac{1}{\operatorname{Pr}}\left(\theta^{\prime \prime}+\frac{\varepsilon}{1+\varepsilon \theta} \theta^{\prime 2}\right)-N b \theta^{\prime} \phi^{\prime}-N t \theta^{\prime 2}-E c f^{\prime \prime 2}-\frac{1}{\operatorname{Pr}} N r \theta^{\prime \prime}=0 \\
& \frac{A}{2} \phi^{\prime} \varsigma-f \phi^{\prime}=\frac{1}{L e}\left(\phi^{\prime \prime}+\frac{N t}{N b} \theta^{\prime \prime}\right)-K r \phi^{n}
\end{aligned}
$$

The boundary conditions are:

i) Blasius problem

$$
\begin{aligned}
& f(0)=0, f^{\prime}(0)=0, \phi^{\prime}(0)=-\left(1-B i_{1} \phi(0)\right), \theta^{\prime}(0)=-\left(1-B i_{2} \theta(0)\right), \\
& f^{\prime}(\infty)=1, \theta(\infty)=0, \phi(\infty)=0
\end{aligned}
$$

ii) Sakiadis problem

$$
\begin{aligned}
& f(0)=0, f^{\prime}(0)=1, \phi^{\prime}(0)=-\left(1-B i_{1} \phi(0)\right), \theta^{\prime}(0)=-\left(1-B i_{2} \theta(0)\right), \\
& f^{\prime}(\infty)=0, \theta(\infty)=0, \phi(\infty)=0,
\end{aligned}
$$

where a prime denotes differentiation with respect to $\varsigma, A=c / a$ is that unsteady parameter, $E=$ $\frac{\omega}{\left(T_{w}-T_{\infty}\right)}$ is viscosity variation parameter, $M=\frac{\sigma B_{0}^{2}(1-c t)}{\rho a}$ is the magnetic field parameter, $K=$ $\frac{v(1-c t)}{k_{0} a}$ is the porosity parameter, $E c=\frac{U_{w}{ }^{2}}{C_{p}\left(T_{\infty}-T_{r}\right)}$, is Eckert number, $U_{w}^{2}=\left(\frac{a x}{1-c t}\right)^{2}, N r=$ $\frac{16 \sigma^{*} T_{\infty}^{3}}{3 k^{*} K}$ is thermal radiation, $\operatorname{Pr}=v / \alpha_{\infty}$ is the Prandtl number, $B i_{1}=\frac{h_{f_{1}}}{k_{\infty}} \sqrt{\frac{v(1-c t)}{a c}}$ is thermal Biot number, $B i_{2}=\frac{h_{f_{2}}}{k_{\infty}} \sqrt{\frac{v(1-c t)}{a c}}$ is concentration Biot number, $\lambda_{T}=\frac{g \beta_{T}\left(T_{w}-T_{\infty}\right)(1-c t)^{2}}{a^{2} x}$ is a thermal buoyancy, $\lambda_{C}=\frac{g \beta_{c}\left(C_{w}-C_{\infty}\right)(1-c t)^{2}}{a^{2} x}$, is concentration buoyancy.

From the engineering point of view, the important characteristics of the flow are the skin-friction coefficient, the local Nusselt and Sherwood numbers, respectively defined as

$$
C_{f}=\frac{\tau_{w}}{\rho U_{w}{ }^{2} / 2}, N u_{x}=\frac{x q_{w}}{k_{\infty}\left(T_{w}-T_{\infty}\right)}, S h_{x}=\frac{x j_{w}}{D_{B}\left(C_{w}-C_{\infty}\right)}
$$

where the skin friction $\tau_{w}$ and the heat and mass transfer $q_{w}, j_{w}$ from the surface are given by:

$$
\tau_{w}=\mu\left(\frac{\partial u}{\partial y}\right)_{y=0} ; q_{w}=-k\left(\frac{\partial T}{\partial y}\right)_{y=0}, j_{w}=-D_{B}\left(\frac{\partial C}{\partial y}\right)_{y=0}
$$

Substituting eqs. (9) into (15) and (16), we obtain

$$
\operatorname{Re}_{x}^{1 / 2} C f=\left(1+\frac{1}{(1+E \theta)}\right) f^{\prime \prime}(0), \operatorname{Re}_{x}^{-1 / 2} N u=-\left(1+\frac{4}{3} R+\varepsilon \theta^{\prime}(0)^{2}+\varepsilon\right) \theta^{\prime}(0), \operatorname{Re}_{x}^{-1 / 2} S h=-\phi^{\prime}(0)
$$

where $R e_{x}=\frac{U_{w} x}{v_{f}}$ is the local Reynolds number.

\section{Results and Discussion}

o achieve a strong approval of the physical model, numerical solutions for the dimensionless velocity, temperature, and concentration fields are presented graphically for various values of Eckert number, Biot numbers due to thermal and diffusion, chemical reaction parameter, Brownian motion parameter, thermophoresis parameter, thermal radiation 
parameter, magnetic field parameter and porosity parameter appearing in the problem in the presence $(E=0.2, \varepsilon=0.2)$ and absence $(E=0, \varepsilon=0)$ of viscosity variation and conductivity variation parameters. Moreover, the representative results for the local friction factor coefficient, rate of heat transfer in terms of Nusselt number, and rate of mass transfer in terms of Sherwood number have explained the influence of different physical parameters of the flow, being recorded through tables for both Sakiadis and Blasius fluid flows. For numerical solutions we have chosen the non-dimensional parameter values as $K=0.5, n=2 ; K r=$ $0.2, \operatorname{Pr}=0.2, \lambda_{T}=3, \lambda_{c}=1, E c=0.2, N b=0.3, N t=0.2, M=0.5, B i_{1}=B i_{2}=0.2, E=$ $0.2, \varepsilon=0.2, N r=0.5$. These numeric values are preserved as common in the entire study apart from the variations in the corresponding figures and tables. In this study, the graphs in solid and dashed lines indicate the Sakiadis and Blasius flow cases, respectively. Also, the color variations with variable properties and without variable properties.

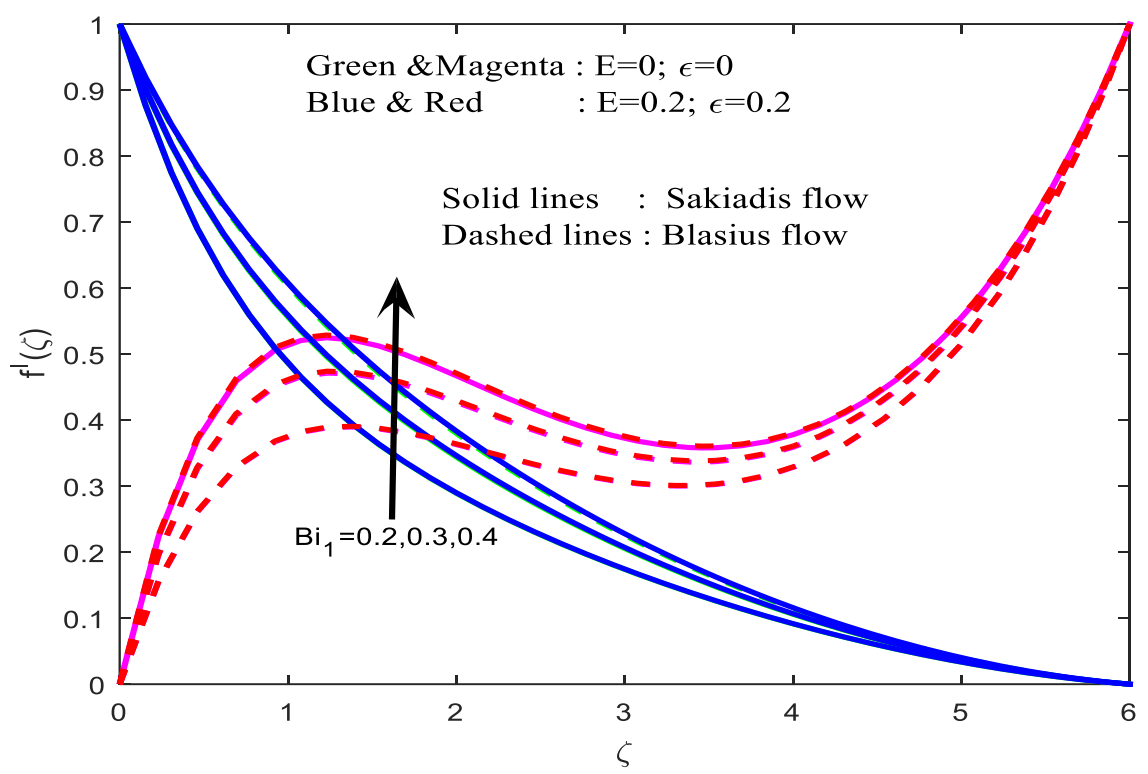

Figure 2. Velocity profiles for different values of $B i_{1}$.

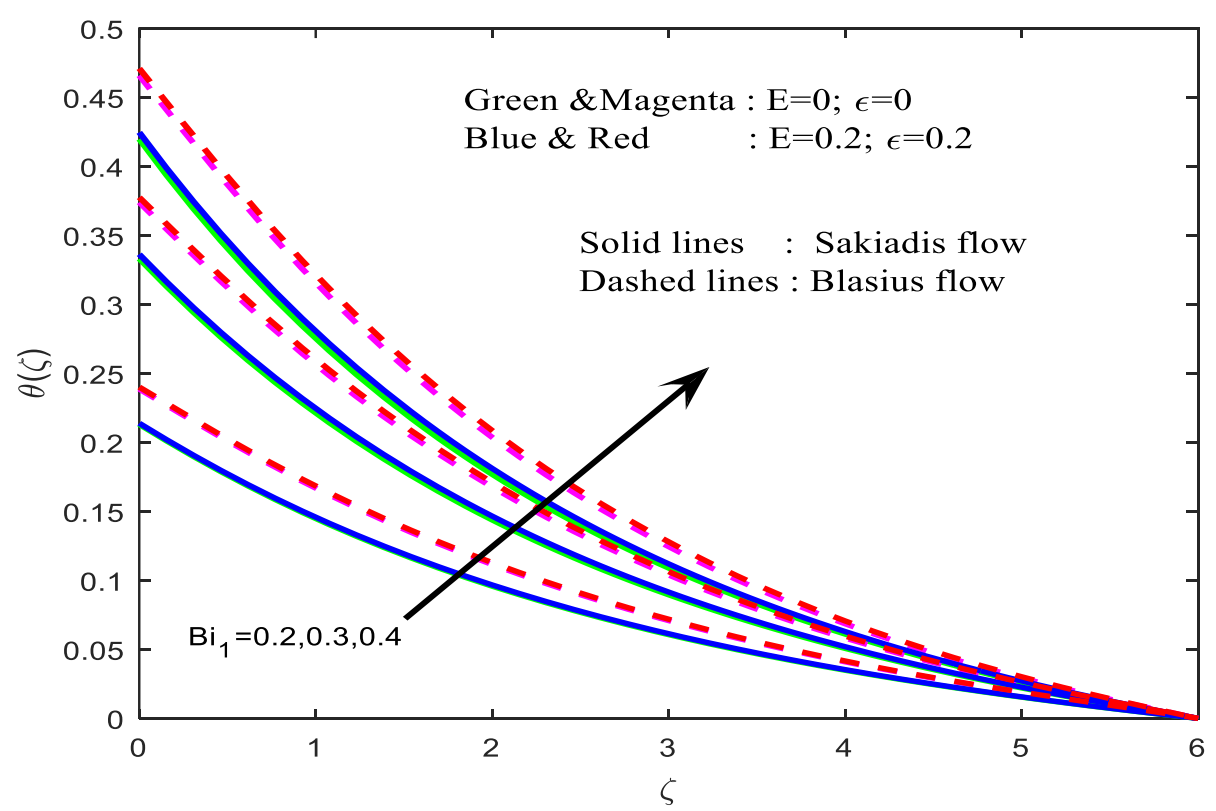

Figure 3. Temperature profiles for different values of $B i_{1}$. 
Figures 2-4 illustrate that the influence of Biot number due to thermal $B i_{1}$ on the velocity, temperature, and concentration distributions. It is noticed that in Figure 2 the velocity increases rapidly near the boundary with an increase in Biot number $B i_{1}$. In Figure 3 , we present the behavior of Biot number $B i_{1}$ on the thermal boundary layer. Biot number is defined as the ratio of convection heat transfer to conduction heat transfer. As increase in Biot number generates a temperature at the plate, which creates a thicker thermal boundary layer, while the same phenomena can be observed in concentration distribution (see in Figure 4). The diffusion Biot number $\mathrm{Bi}_{2}$ enhances the velocity, temperature, and concentration distributions in both Blasius and Sakiadis fluid flow cases (Figure 5-7). It is also interesting to mention that the Blasius flow has a higher thermal and diffusion boundary layer compared to Sakiadis flow.

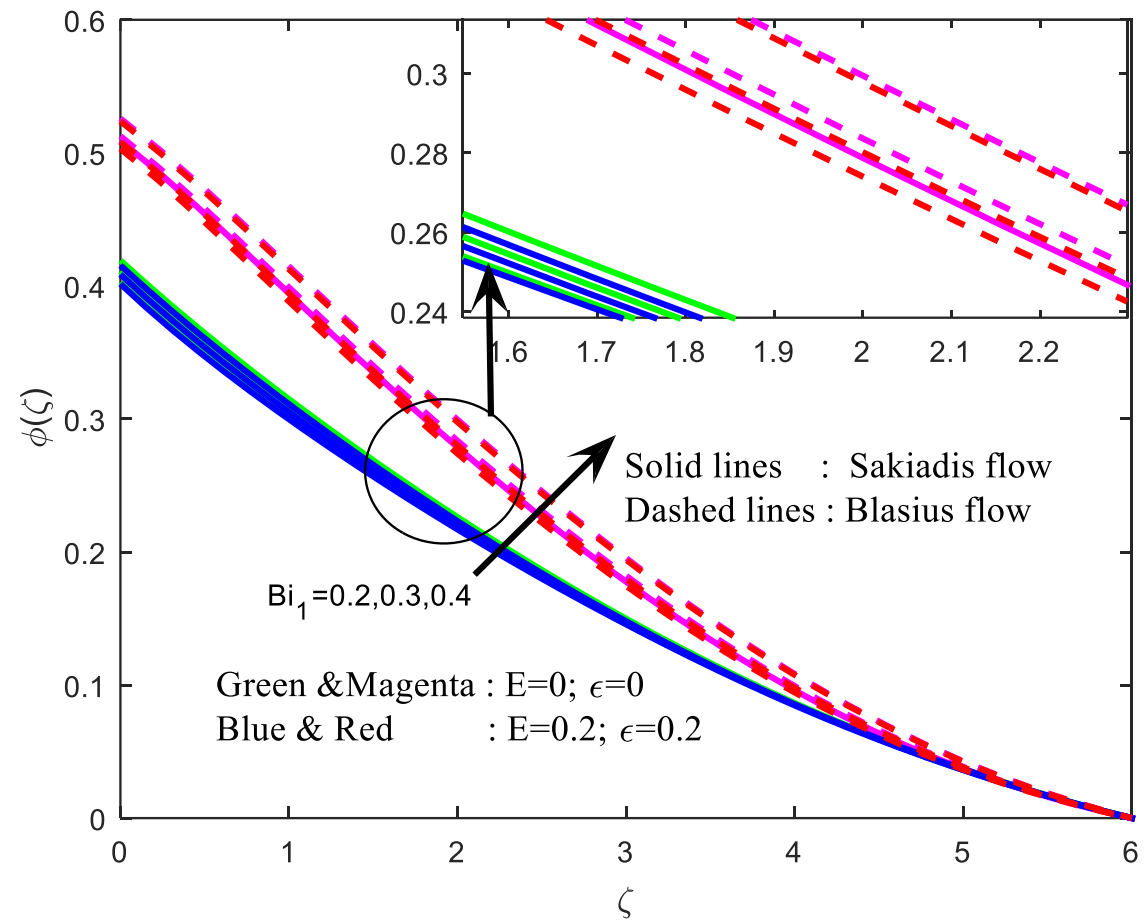

Figure 4. Concentration profiles for different values of $B i_{1}$.

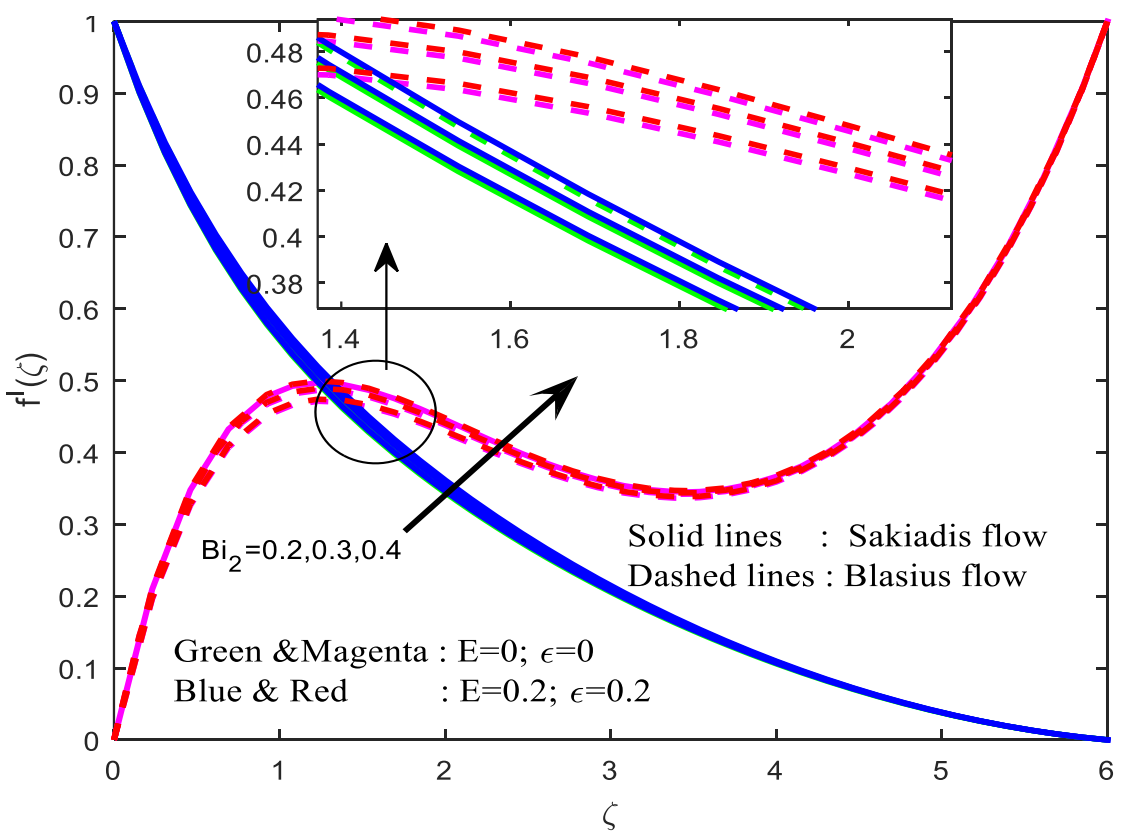

Figure 5. Velocity profiles for different values of $B i_{2}$. 


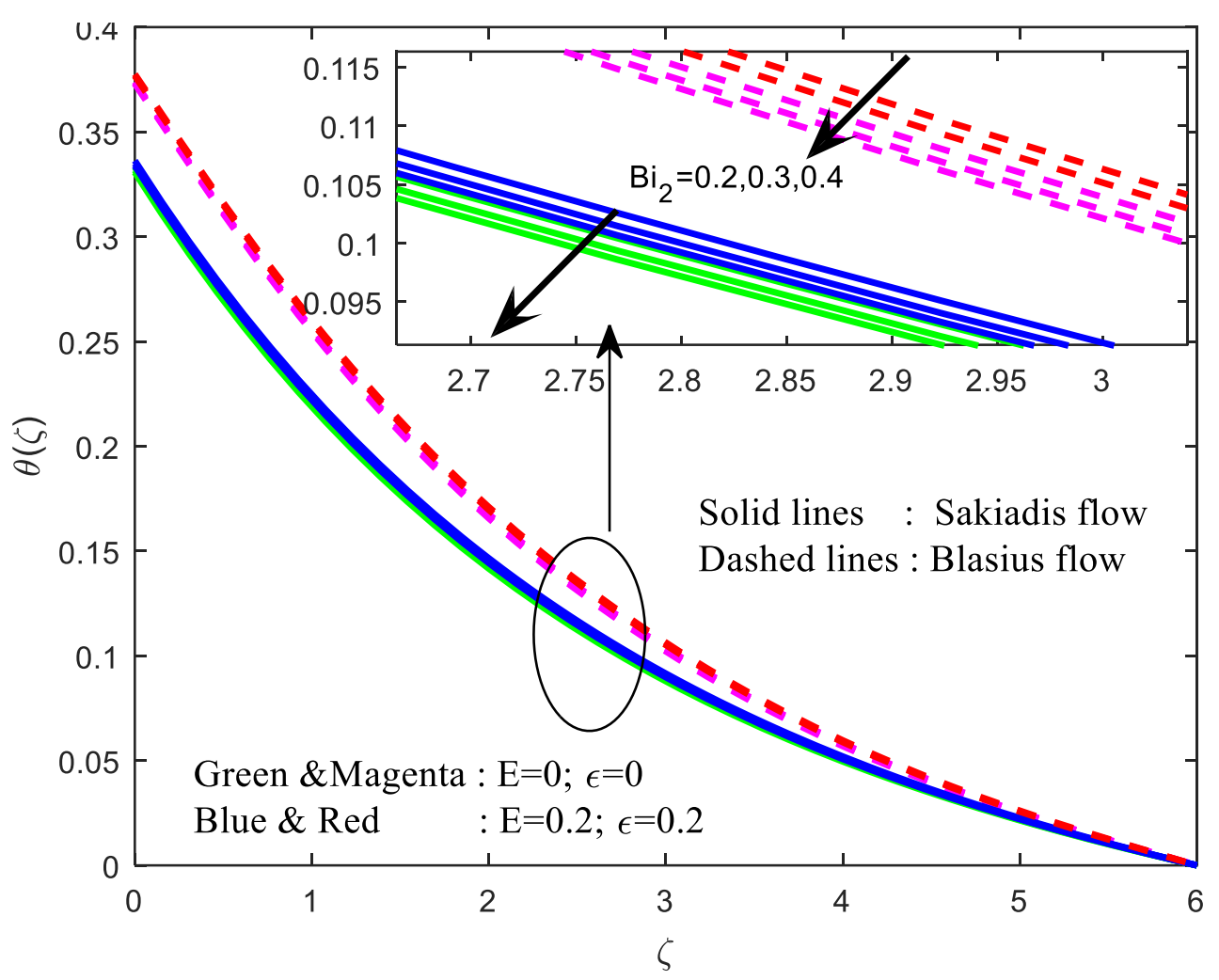

Figure 6. Temperature profiles for different values of $B i_{2}$.

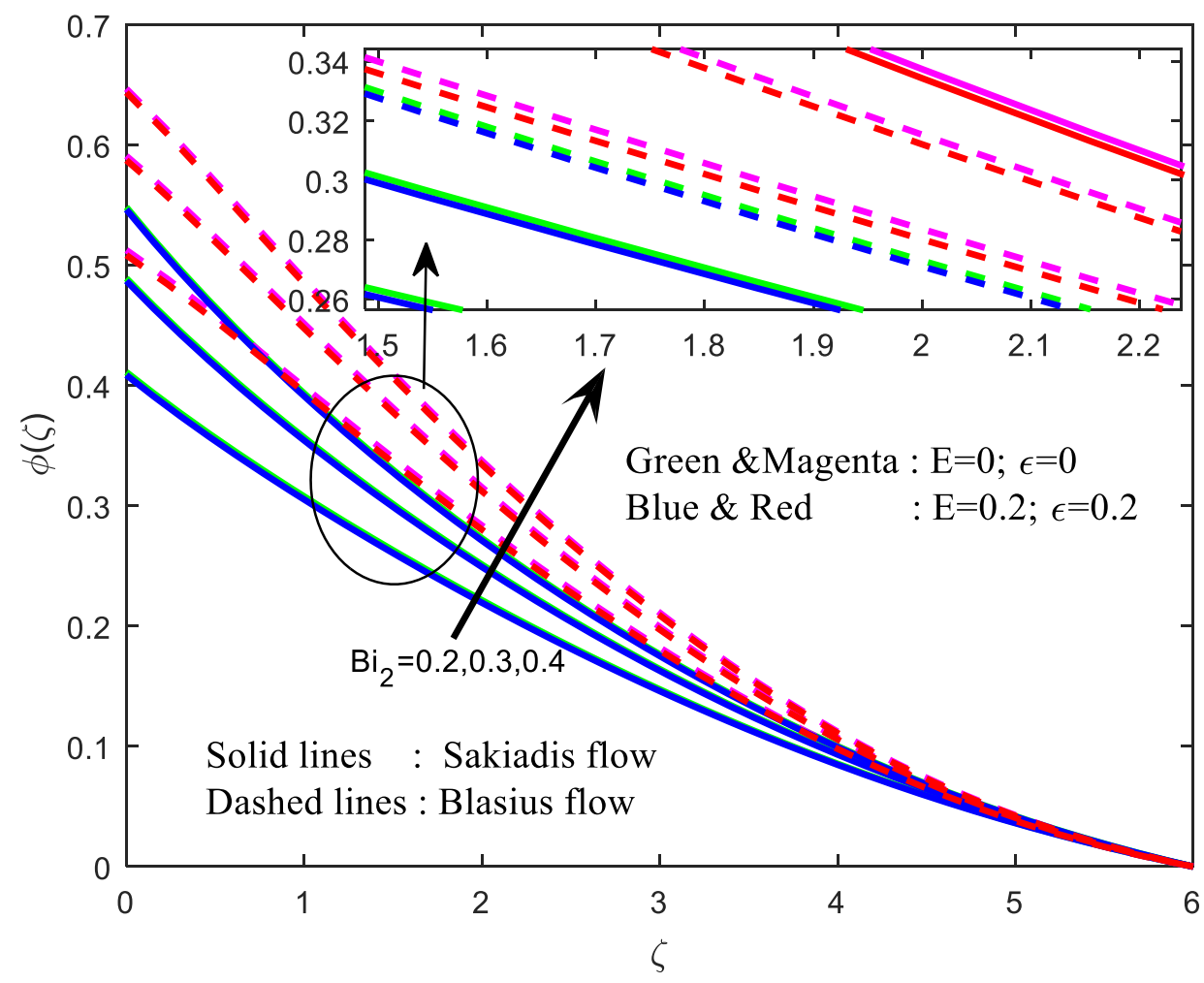

Figure 7. Concentration profiles for different values of $B i_{2}$.

The influence of Eckert number $E c$ on dimensionless velocity and temperature profiles in the presence and absence of viscosity variation parameter and conductivity variation parameter are presented in Figures 8-9 in both Blasius and Sakiadis fluid flow cases. In the momentum and continuity equations, the dimensionless Eckert number $E c$ does not directly enter its influence come through in the energy equation. It is observed the effect of $E c$ on 
velocity in the presence of buoyancy force. So, the momentum boundary layer thickness increases with an increase in $E c$ and also increases the thermal boundary layer thickness for small values of an Eckert number.

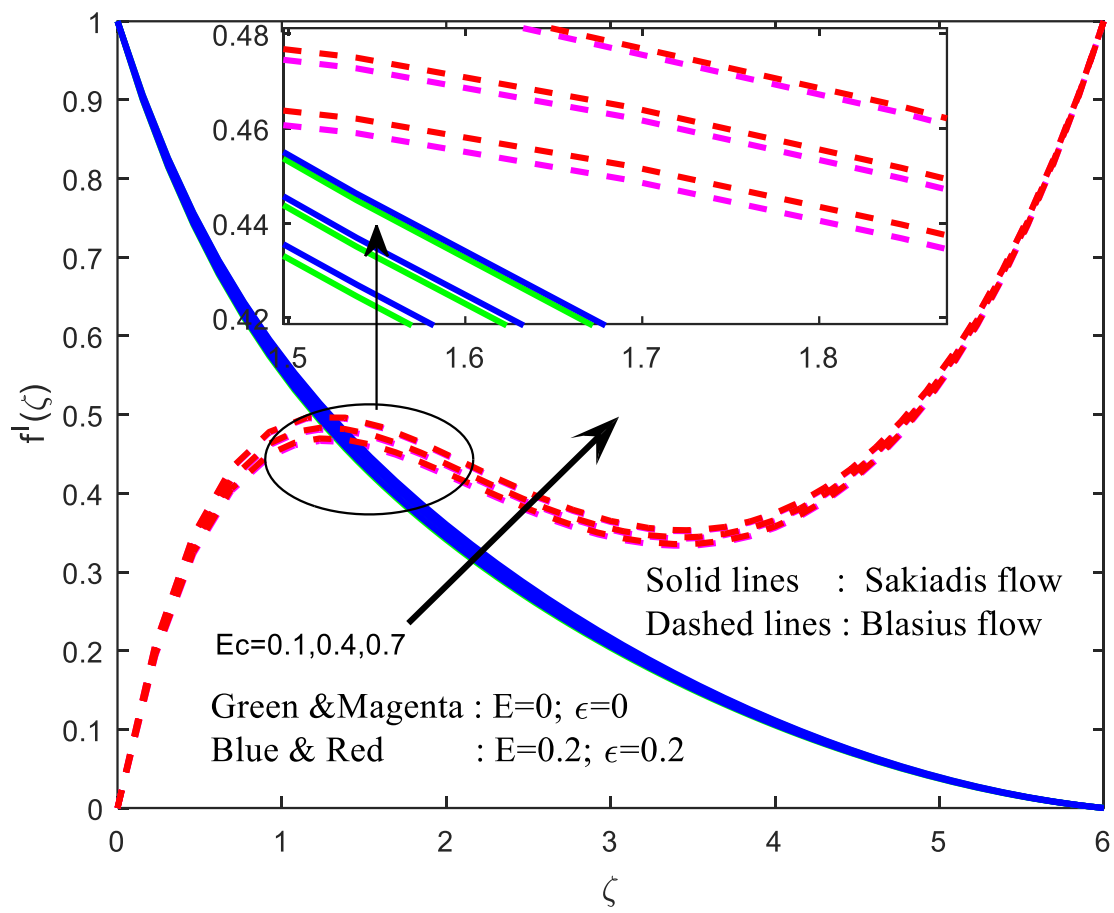

Figure 8. Velocity profiles for different values of $E c$.

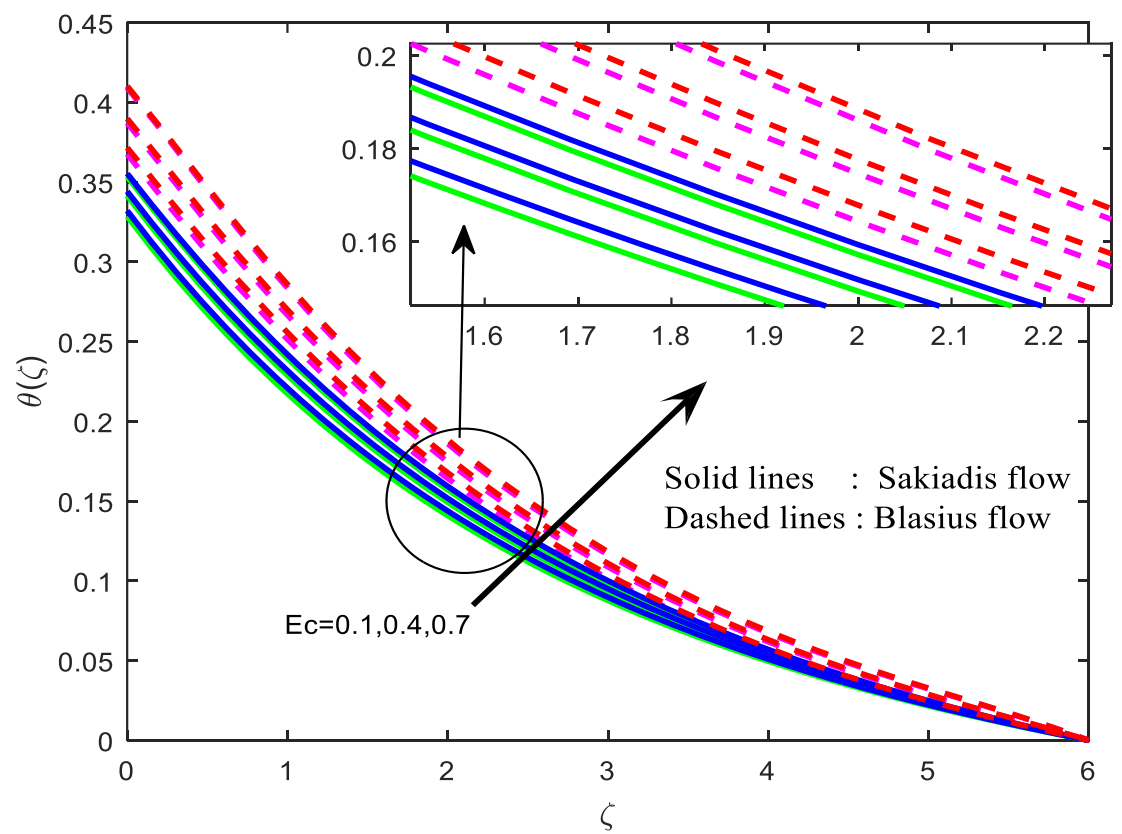

Figure 9. Temperature profiles for different values of $E c$.

The effect of the magnetic field parameter on velocity, temperature, and concentration profiles in Figures 10-12. It is found that as an increasing magnetic field, we can notice that deceleration in the velocity and enhancement in temperature and concentration fields. Physically, this result quantitatively agrees with expectations. This is due to the fact that the application of a magnetic field on an electrically conducting fluid gives rise to resistive type force (retardation force), known as Lorentz force. This force tends to slow down the motion of the boundary layer and to enhance the increase in concentration and temperature distributions in both Blasius and Sakiadis fluid flows. 


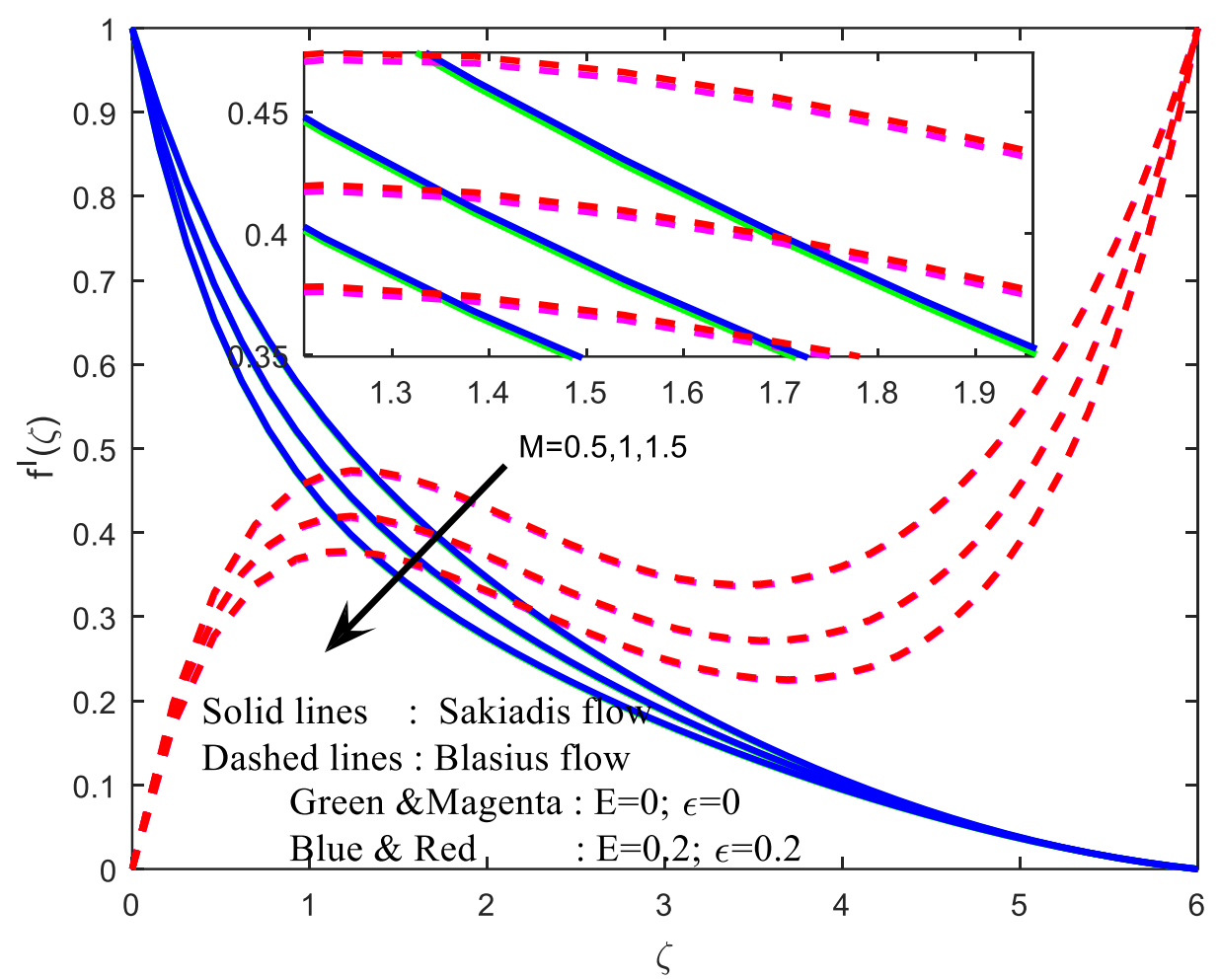

Figure 10. Velocity profiles for different values of $M$.

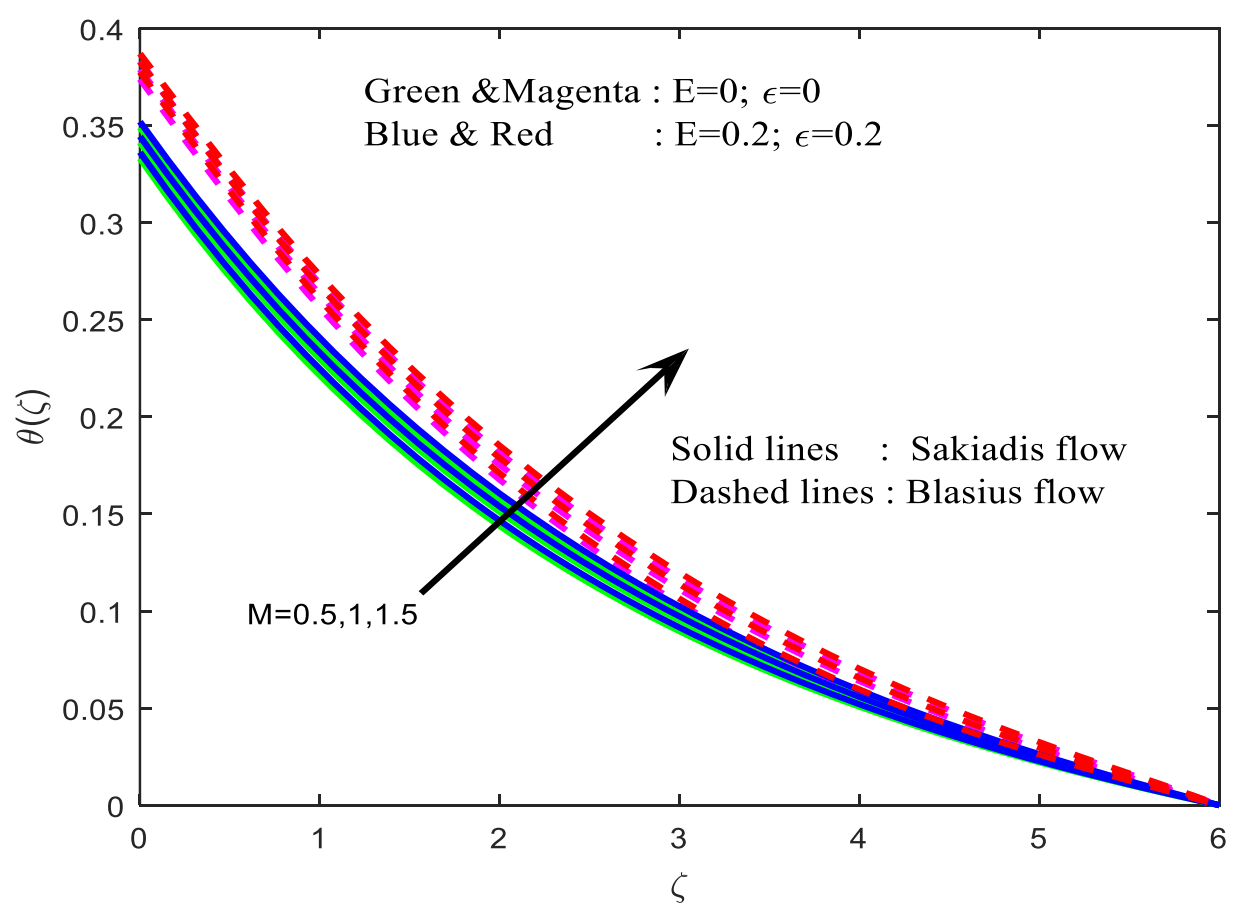

Figure 11. Temperature profiles for different values of $M$.

For different values of thermal radiation parameter $\mathrm{Nr}$ on dimensionless velocity, temperature, and concentration fields are shown in Figures13-15. It is seen that thickness of the momentum and thermal boundary layer increases as $N r$ increases. It is clear that an increase in the value of $\mathrm{Nr}$ implies an increase of thermal radiation in the thermal boundary layer, which results in an increase in the value of the temperature profile in the thermal boundary layer. The opposite phenomena can be observed in Concentration profiles (Figure 15). 


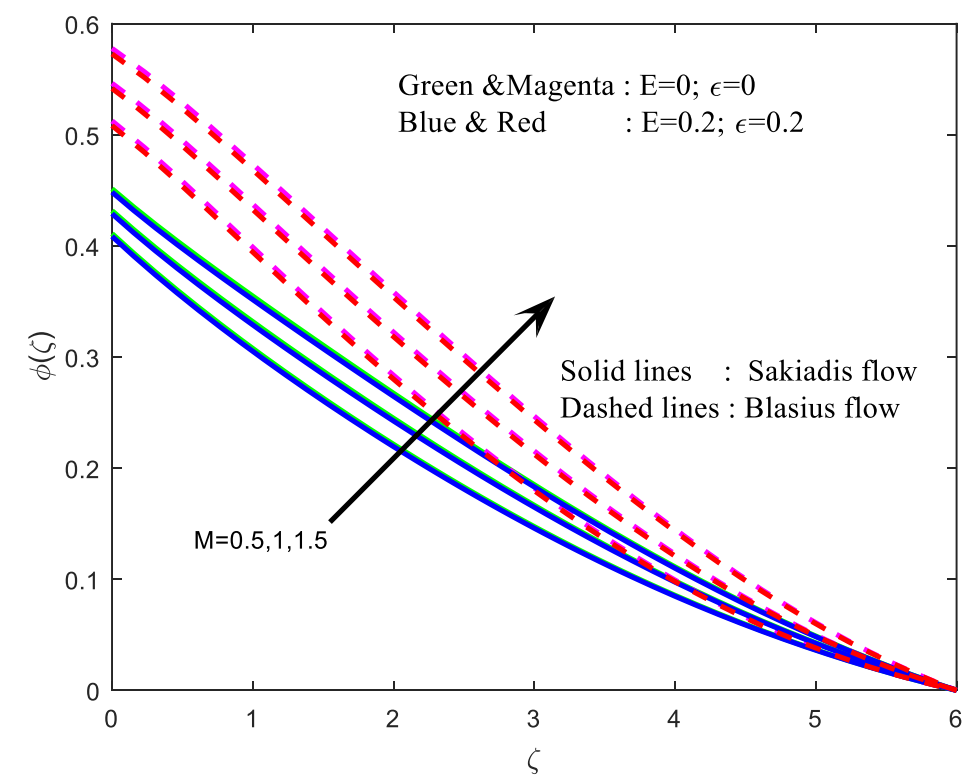

Figure 12. Concentration profiles for different values of $M$.

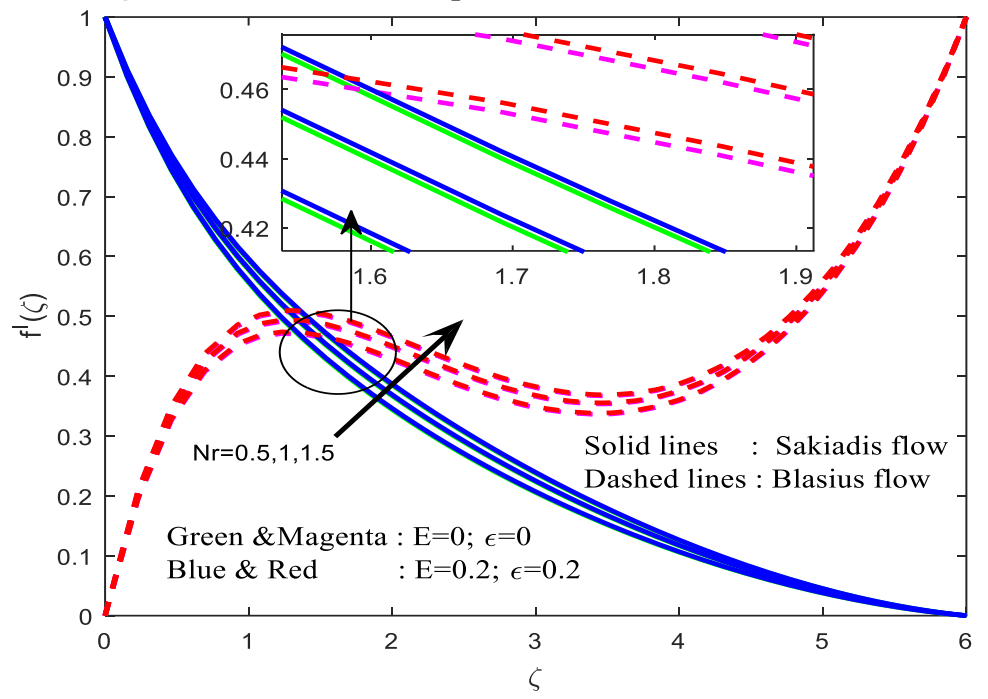

Figure 13. Velocity profiles for different values of $\mathrm{Nr}$.

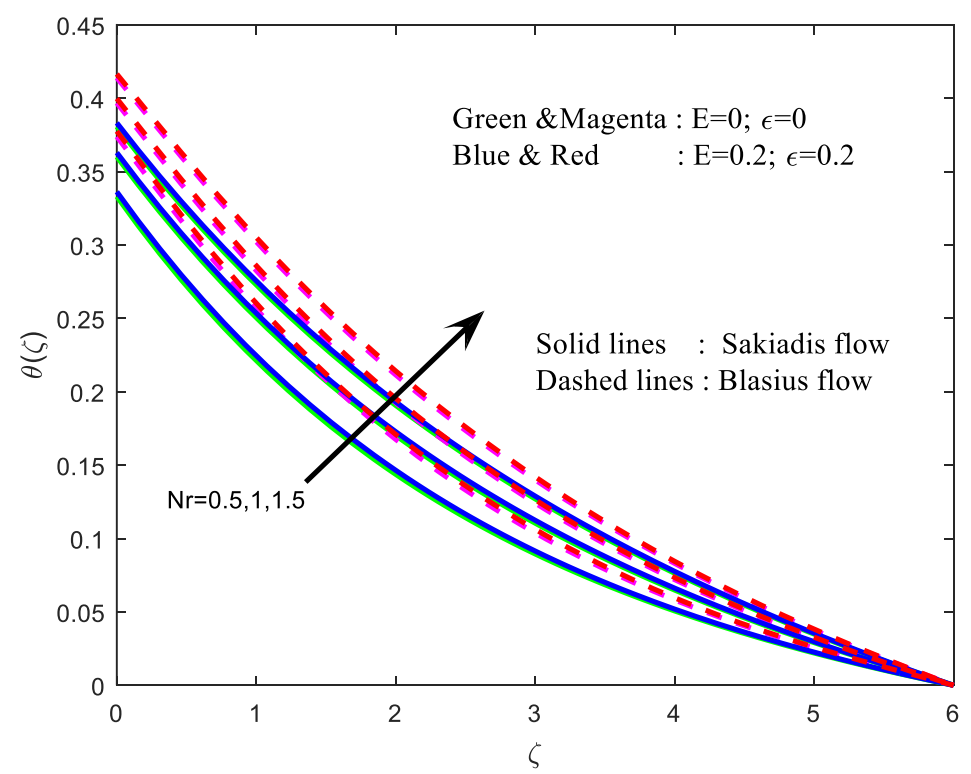

Figure 14. Temperature profiles for different values of $\mathrm{Nr}$. 


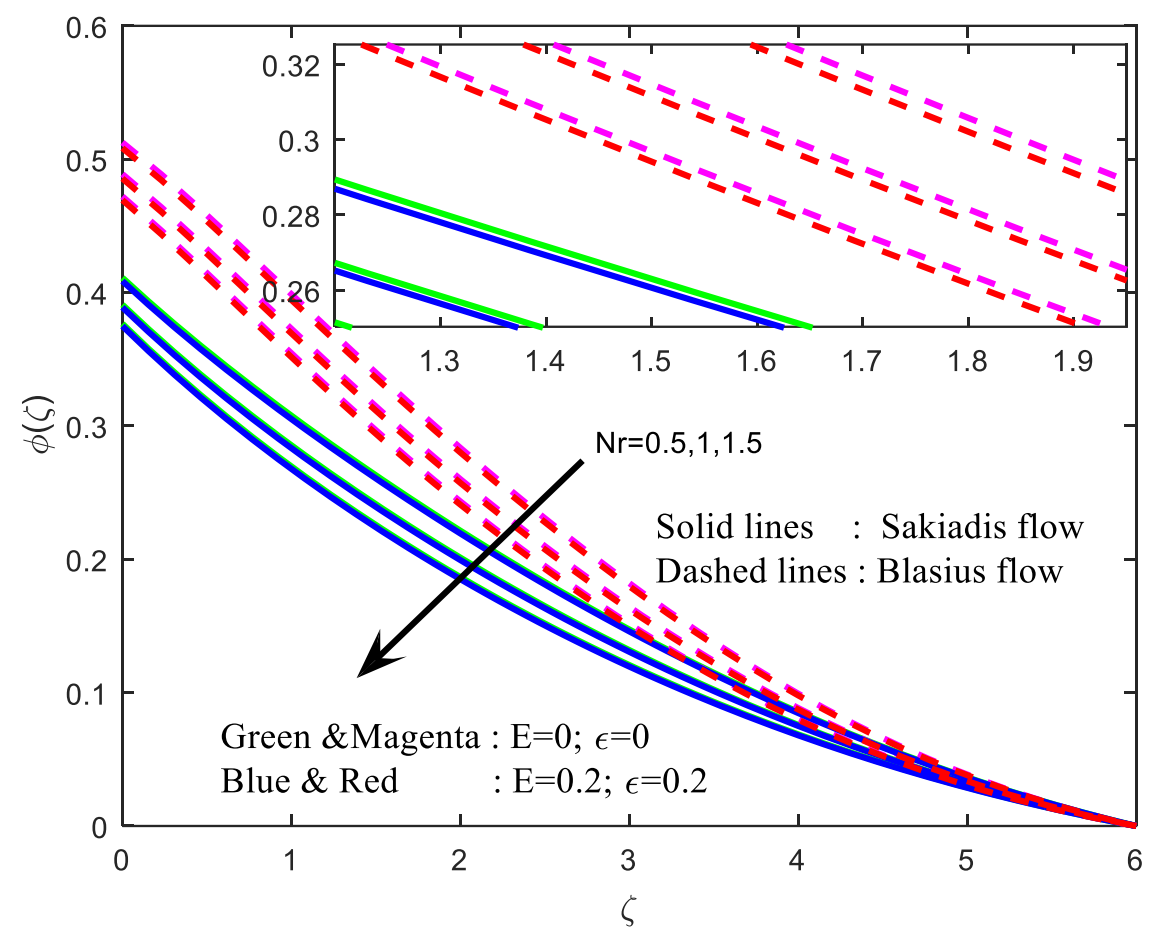

Figure 15. Concentration profiles for different values of $\mathrm{Nr}$.

The analysis of Brownian motion $N b$ is a key parameter prepared to present on temperature and concentration profiles (see Figures 16-17). Figure 16 illustrates the typical temperature for different values of Brownian motion $\mathrm{Nb}$. The temperature of the fluid increases and the concentration of the fluid decreases with an increase in small values of $\mathrm{Nb}$. Physically, it is very interesting to notice that the Brownian motion of nanoparticles at molecular and nanoscale levels is a key nanoscale mechanism governing their thermal behavior. It is due to the fact that, in a Nanoscale system, the Brownian motion of the nanoparticles $\mathrm{Nb}$ takes place, affect the heat transfer properties. The particle size scale approaches to the nanometer scale, the particle Brownian motion $\mathrm{Nb}$, and its effect on the surrounding liquids play an important role in the heat transfer.

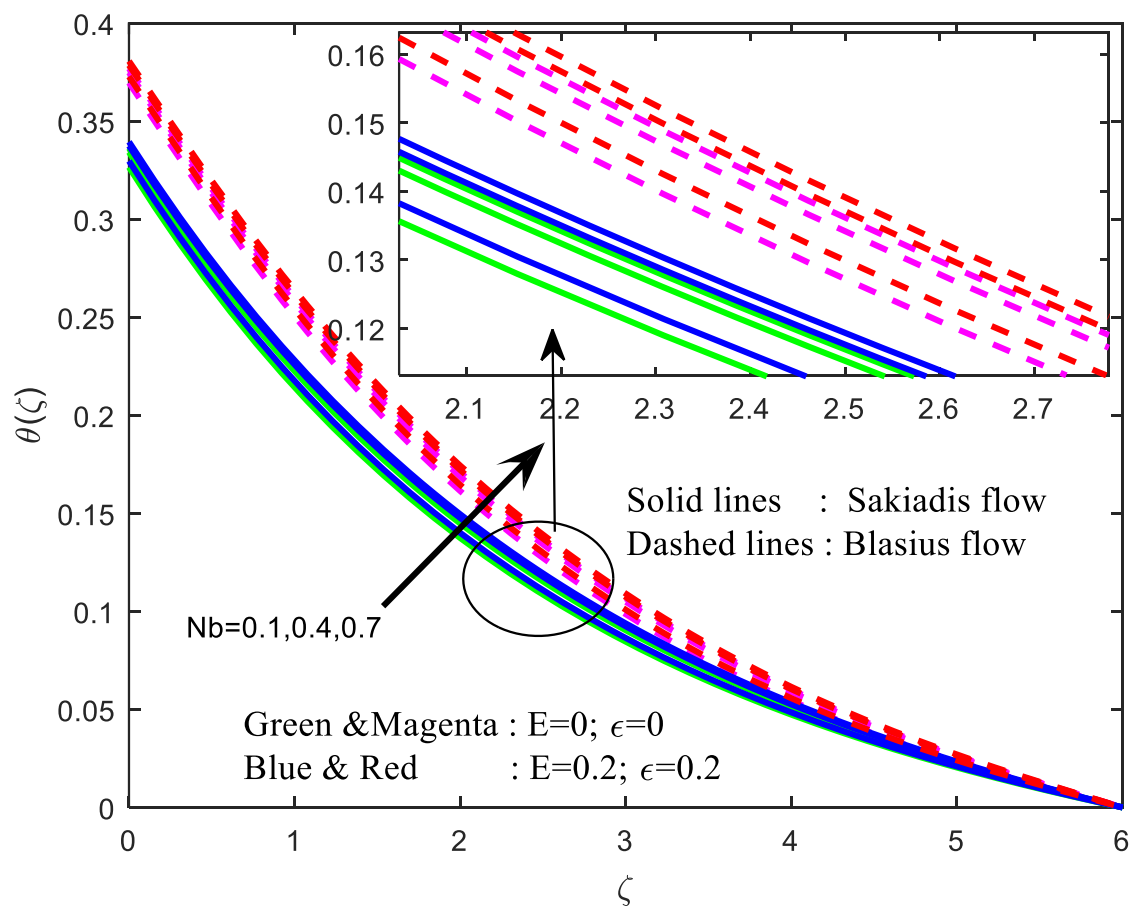

Figure 16. Temperature profiles for different values of $\mathrm{Nb}$. 


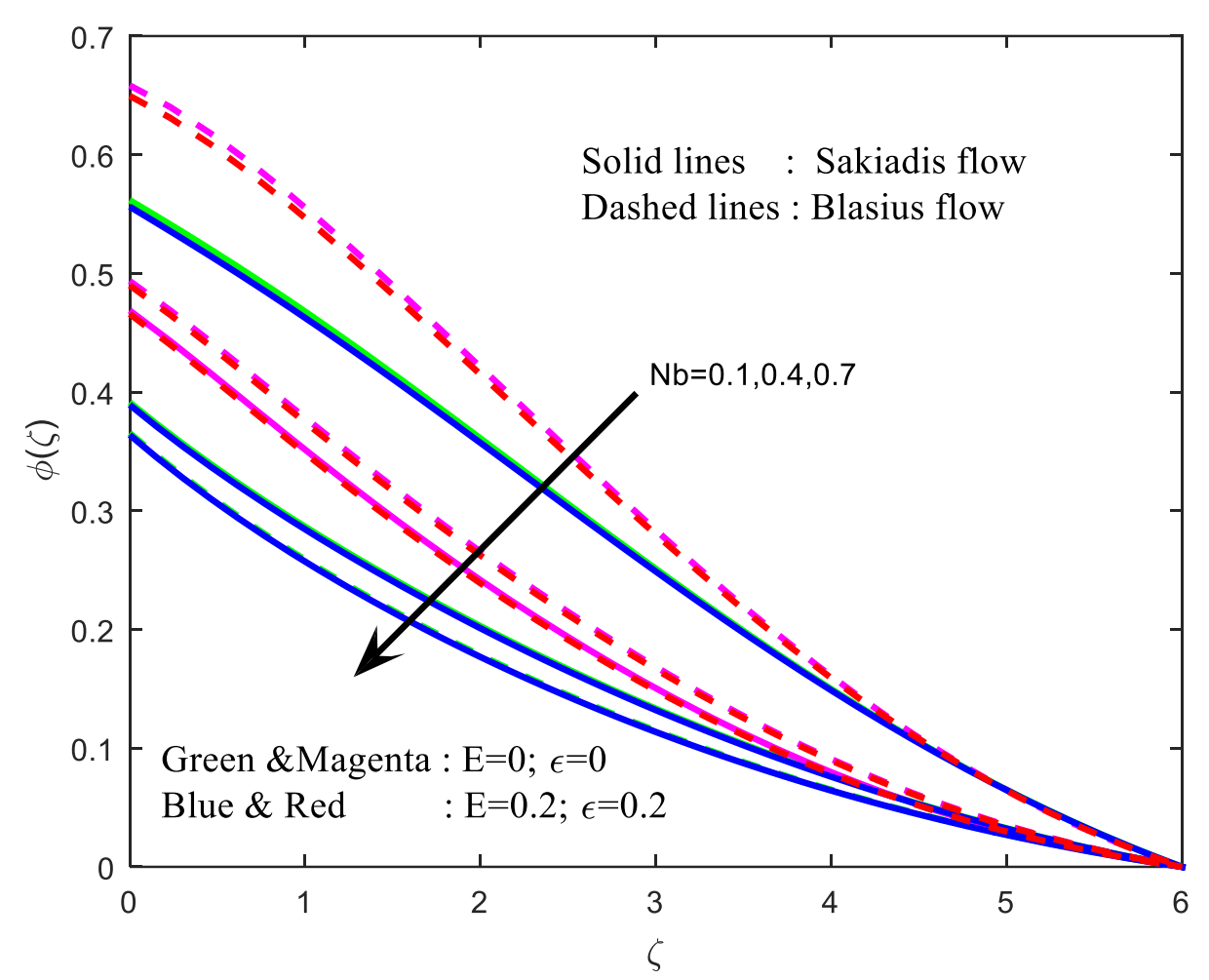

Figure 17. Concentration profile for different values of $\mathrm{Nb}$.

Figures 18-20 depict the effect of the thermophoresis parameter on temperature, concentration, and velocity distributions. It is observed that the temperature of the fluid decreases, whereas the concentration and velocity distributions, increase with the increase in the thermophoresis parameter. We found that the positive values of the thermophoresis parameter act as a cold surface (The temperature variation is not enough to dominate), while negative values act as a hot surface. For hot surfaces, the thermophoresis trends to the nanoparticles boundary layer way from the surface since the hot surface repels the sub-micron sized particle, forming a relatively particle-free layer near the surface in both the presence and absence of viscosity variation parameter and conductivity variation parameter for Blasius and Sakiadis fluid flow cases.

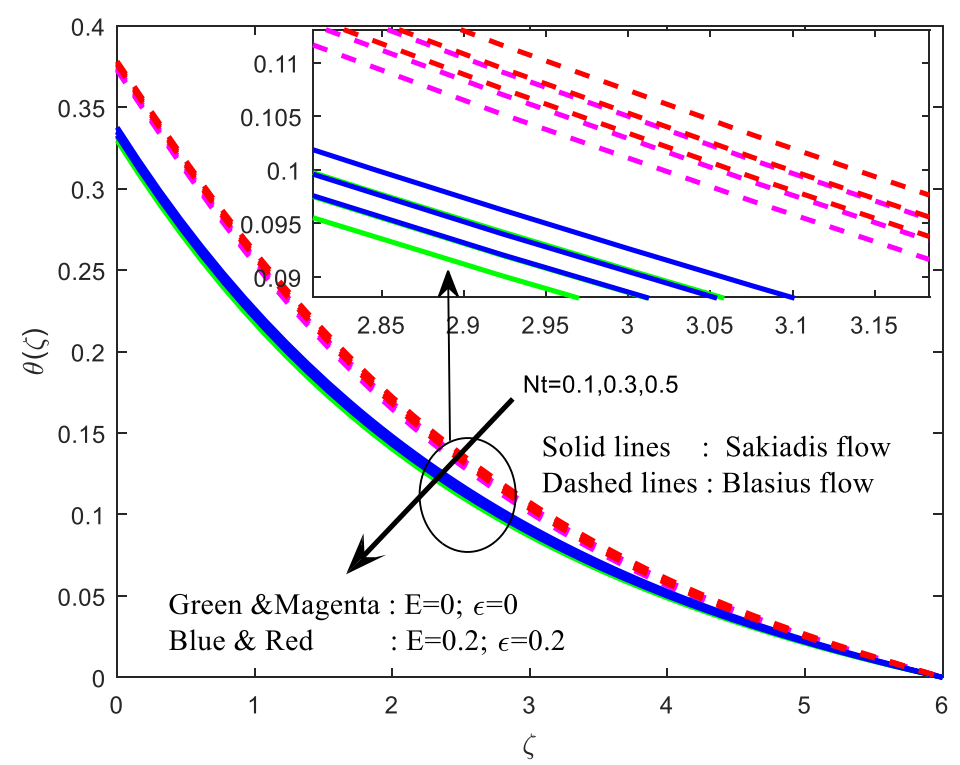

Figure 18. Temperature profiles for different values of $N t$. 


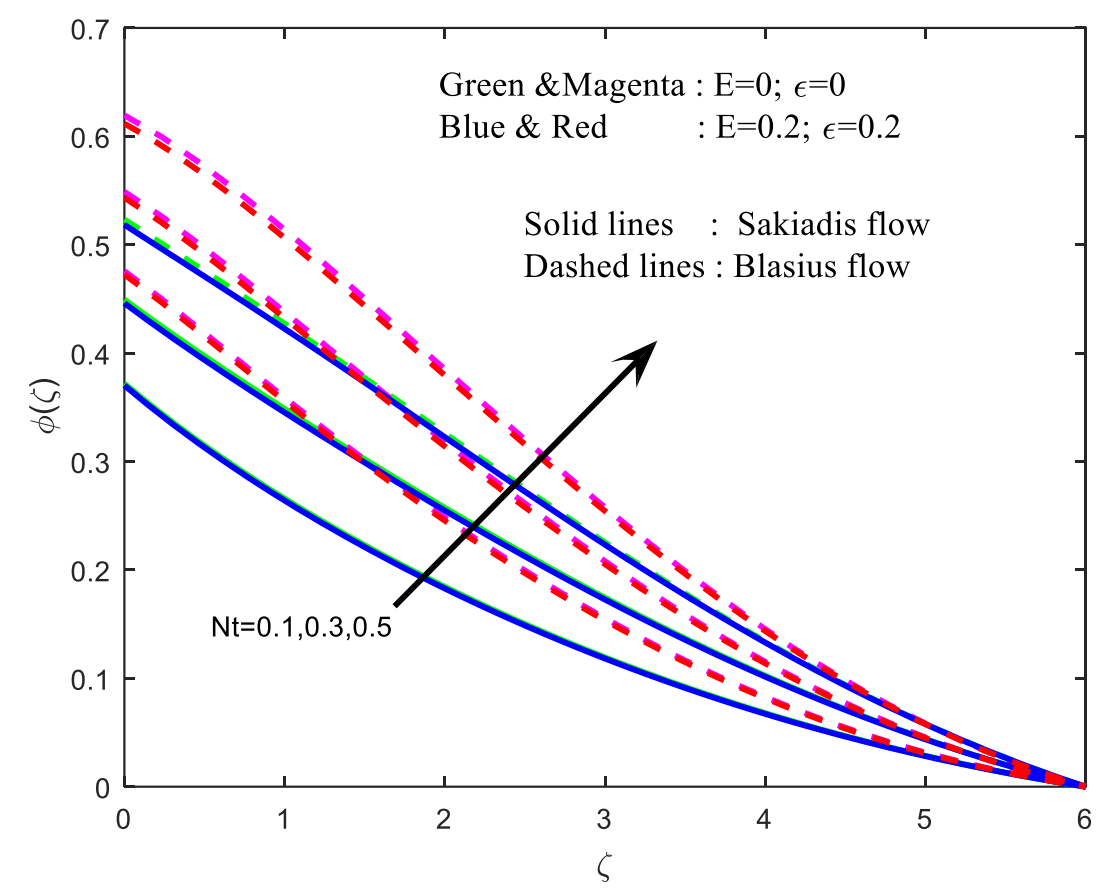

Figure 19. Concentration profiles for different values of $N t$.

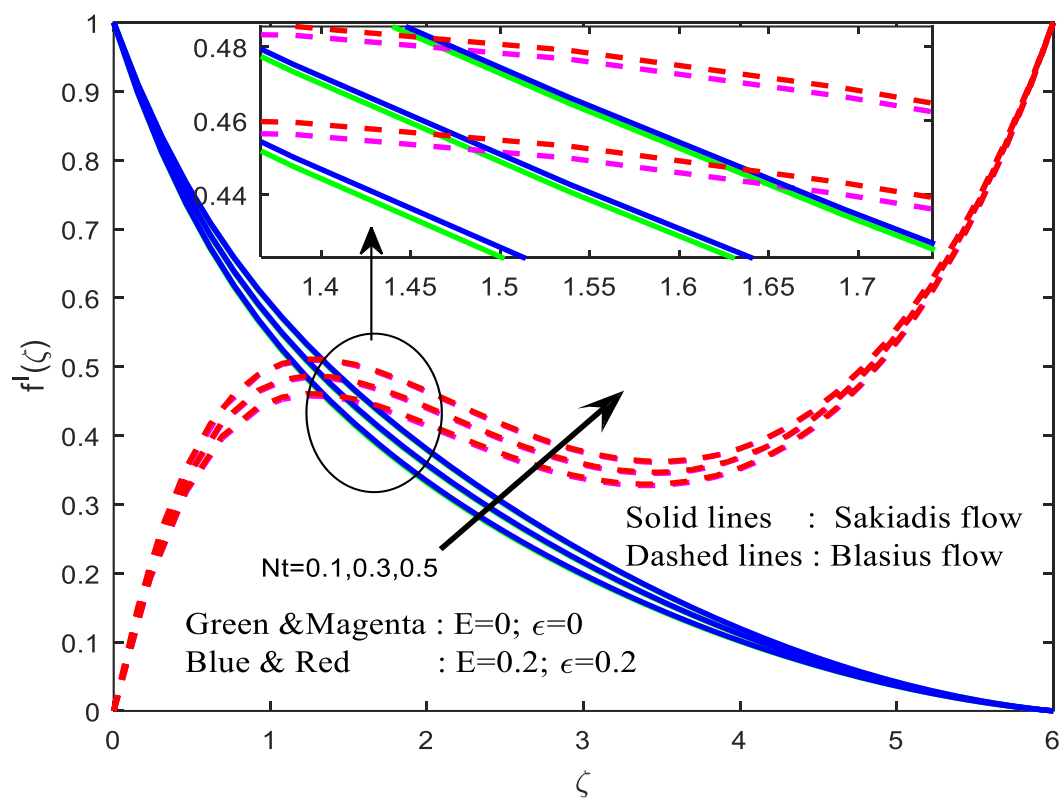

Figure 20. Velocity profiles for different values of $N t$.

In Figures 21-23 is represented the influence of the porosity parameter on dimensionless velocity, temperature, and concentration fields. It is obvious that in Figure 21, the presence of a porous medium causes a high restriction to the fluid flow and then slowdowns its motion. Therefore, with an enhance in the porosity parameter, the resistance to the fluid flow rises, suppressing the velocity of the fluid in both Blasius and Sakiadis fluid flow cases. The opposite trend can be observed in temperature and concentration fields (Figures 22-23).

The influence of the chemical reaction parameter is sketched in Figure 24. The increasing the values of the chemical reaction parameter decelerate the concentration profiles for Blasius and Sakiadis cases. It is due to the fact that the chemical reaction in this system results in the consumption of chemicals and hence results in decelerating the concentration distributions. The most important effect is that the chemical reaction tends to diminish the solutal boundary layer thickness. 


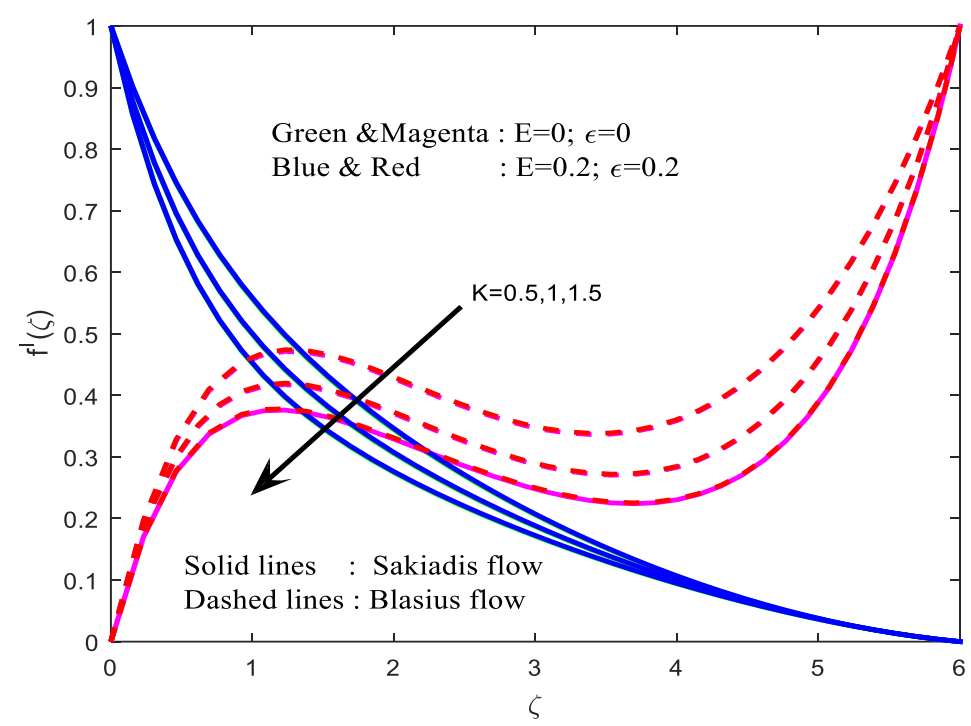

Figure 21. Velocity profiles for different values of $K$.

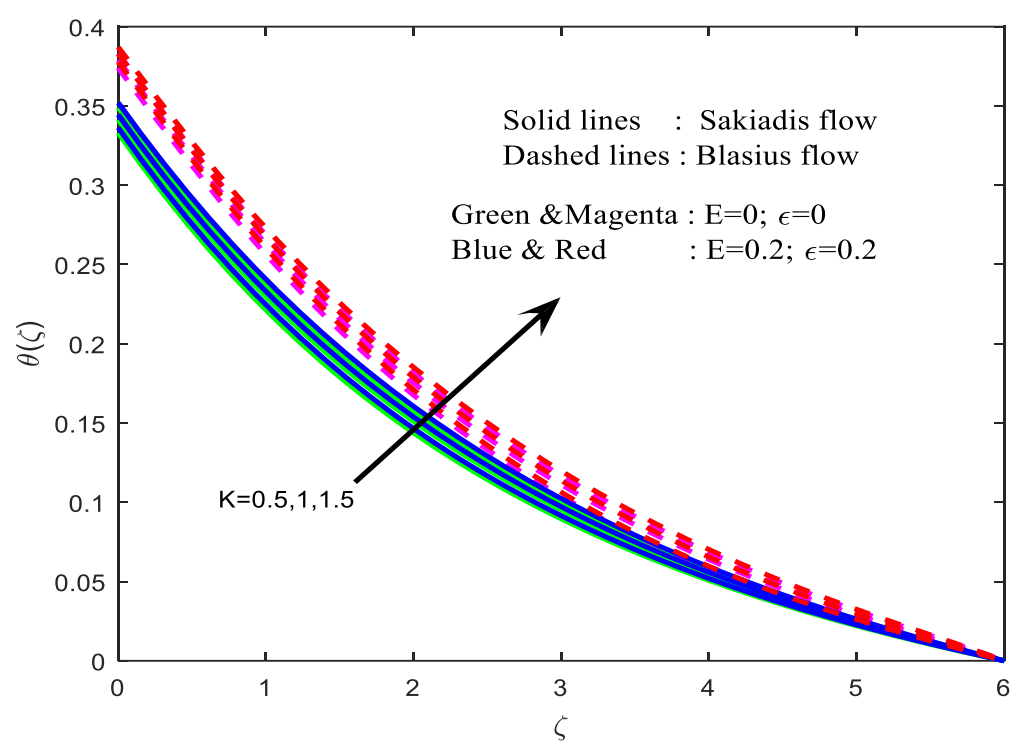

Figure 22. Temperature profiles for different values of $K$.

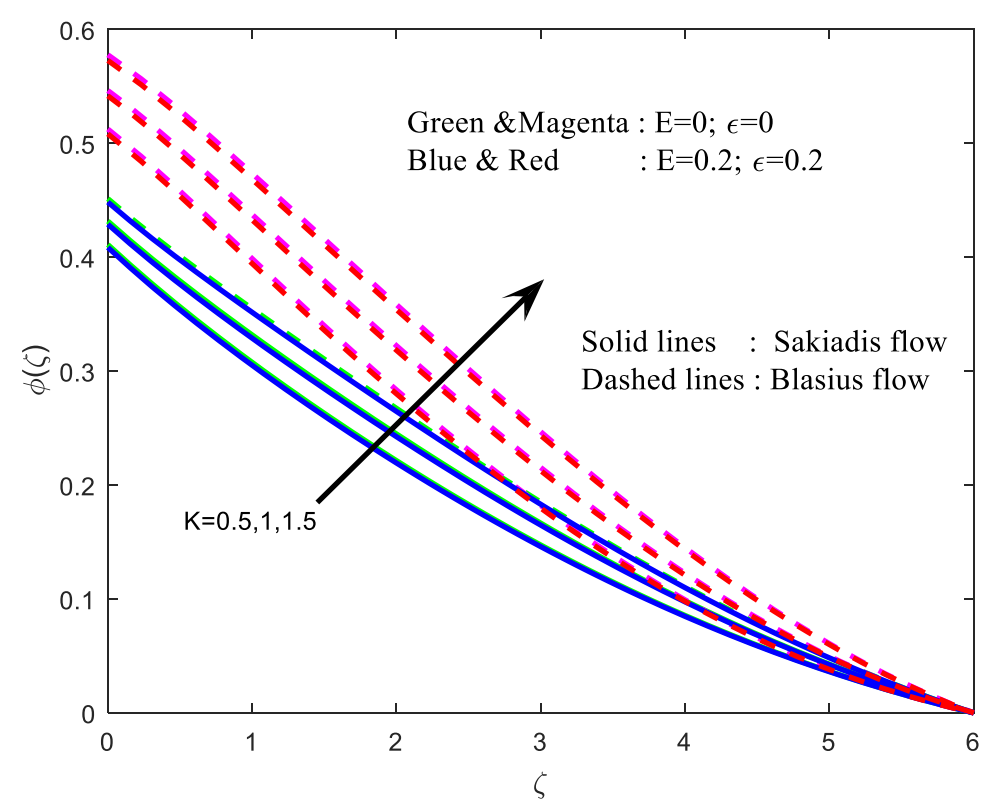

Figure 23. Concentration profiles for different values of $K$. 


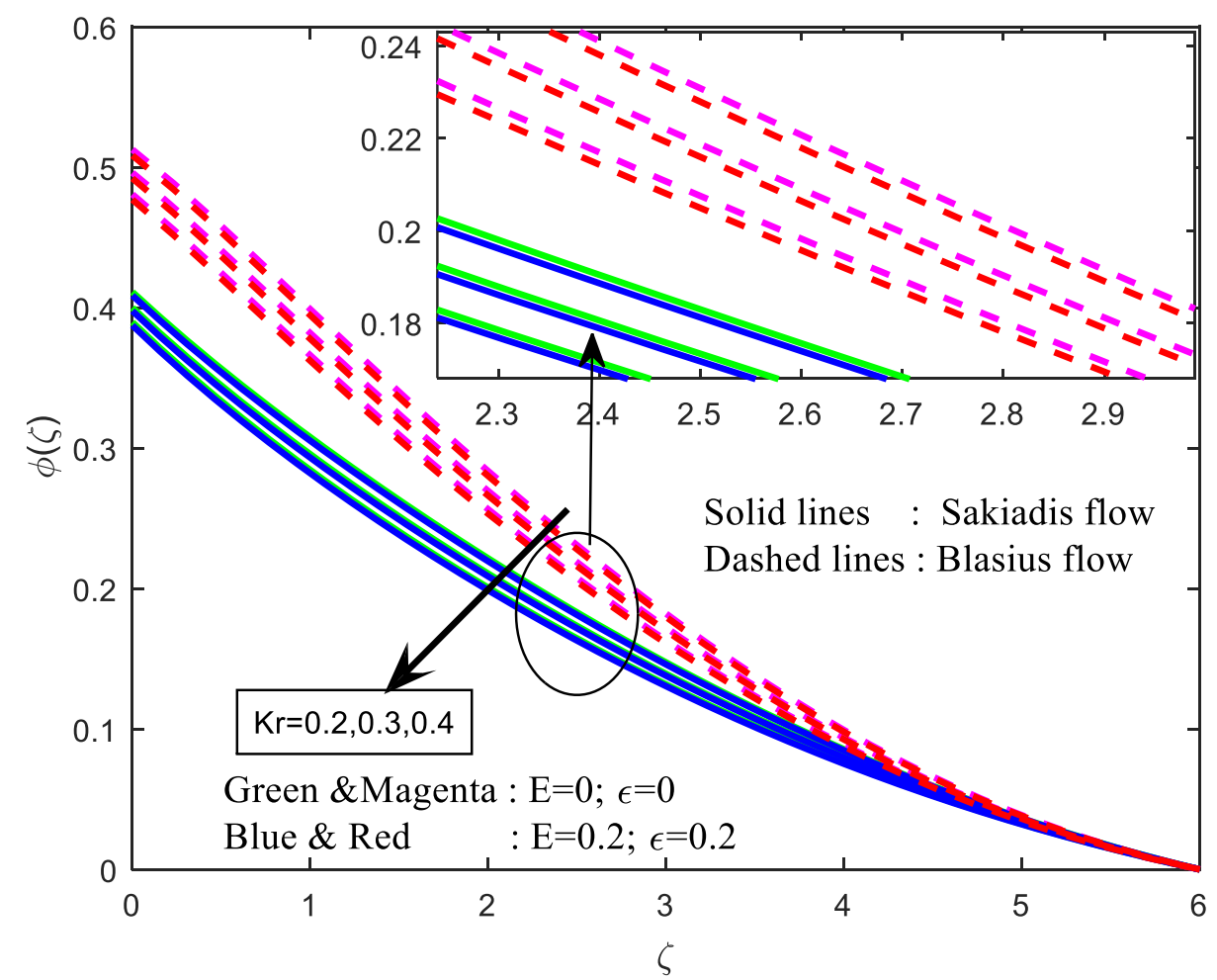

Figure 24. Concentration profiles for different values of $\mathrm{Kr}$.

From Table 1 we have to see that the present results are in good agreement compared to previous results in the absence of Eckert number, porosity parameter, chemical reaction parameter, and Biot numbers with $[12,13,14]$ in both Blasius and Sakiadis flow cases. The present results are discussed the effects of physical parameters, namely an unsteady parameter, thermal buoyancy parameter, and Prandtl number, on heat transfer characteristics.

Table 1. Comparison of some of the values of the wall temperature gradient $-\theta^{\prime}(0)$ with the present results in the absence of thermal radiation when $E c=K=B i_{1}=B i_{2}=K r=0$.

\begin{tabular}{|c|c|c|c|c|c|}
\hline$\lambda_{T}$ & $\operatorname{Pr}$ & [12] & [13] & [14] & Present results \\
\hline & 0.01 & 0.0197 & & 0.0197 & 0.019723 \\
\hline & 0.72 & 0.8086 & 0.8058 & 0.8086 & 0.808836 \\
\hline \multirow[t]{4}{*}{0.0} & 1.0 & 1.0000 & 0.9961 & 1.00000 & 1.000000 \\
\hline & 3.0 & 1.9237 & 1.9144 & 1.9237 & 1.923687 \\
\hline & 10.0 & 3.7207 & 3.7006 & 3.7207 & 3.720788 \\
\hline & 10.0 & 12.2940 & - & 12.2941 & 12.30039 \\
\hline 0.0 & 1.0 & - & - & 1.6820 & 1.681921 \\
\hline 1.0 & & - & - & 1.7039 & 1.703910 \\
\hline 1.0 & 1.0 & - & - & 1.0873 & 1.087206 \\
\hline 2.0 & & - & - & 1.1423 & 1.142298 \\
\hline 3.0 & & - & - & 1.1853 & 1.185197 \\
\hline
\end{tabular}

Tables 2, 3, 4 and 5 depict the physical nature of the flow properties at the surface as the variation of skin friction coefficient, heat and mass transfer rates for different pparametersasBiot numbers due to thermal and diffusion $\left(B i_{1}=B i_{2}\right)$, Eckert number, chemical reaction, thermophoresis, Brownian motion, thermal radiation parameter, magnetic field parameter, and porosity parameter are studied in both Blasius and Sakiadis flow cases in the presence $(E=0.2, \varepsilon=0.2)$ and $\operatorname{absence}(E=0, \varepsilon=0)$ of viscosity variation and conductivity variation parameters. It is an obvious that the Eckert number increases the friction coefficient 
and decreases the rate of heat transfer for both Sakiadis and Blasius flows, but decelerates the mass transfer rate (Sherwood number) in Sakiadis fluid flow and increases in Blasius fluid flow. The effect of the thermal radiation parameter increases the friction factor coefficient, heat transfer, as well as mass transfer rates in both Blasius and Sakiadis fluid flow cases. The reverse phenomena can be observed for the magnetic field and porosity parameters. Further, it is interesting to note that the Brownian motion parameter diminishes the skin friction coefficient and heat transfer rate for both Blasius and Sakiadis flows, the heat transfer rate enhances in Sakiadis flow and decelerates in Blasius flow. Theopposite trend can be found in the thermophoresis parameter. The friction factor coefficient, heat, and mass transfer rates increase with the increase in Biot numbers due to temperature and diffusion.

Table 2. Skin friction coefficient and wall temperature gradient concentration gradient for different values of pertinent parameters for Sakiadis fluid flow case.

\begin{tabular}{|c|c|c|c|c|c|c|c|c|c|c|c|c|}
\hline \multirow{2}{*}{$B i_{1}$} & \multirow{2}{*}{$B i_{2}$} & \multirow{2}{*}{$K r$} & \multirow{2}{*}{$E c$} & \multirow{2}{*}{$N b$} & \multirow{2}{*}{$N t$} & \multirow{2}{*}{$N r$} & \multirow{2}{*}{$M$} & \multirow{2}{*}{$K$} & \multicolumn{2}{|c|}{$R e_{x}^{\frac{1}{2}} C f$} & \multicolumn{2}{|c|}{$R e_{x}^{\frac{-1}{2}} N u$} \\
\hline & & & & & & & & & $\begin{array}{l}E=\mathbf{0}, \varepsilon= \\
\mathbf{0}\end{array}$ & $\begin{array}{l}E=0.2 \\
\varepsilon=0.2\end{array}$ & $\begin{array}{l}E=0, \varepsilon= \\
0\end{array}$ & $\begin{array}{l}E=0.2, \\
\varepsilon=0.2\end{array}$ \\
\hline 0.2 & & & & & & & & & -0.88162 & -0.84526 & 0.59023 & 0.59290 \\
\hline 0.3 & & & & & & & & & -0.69823 & -0.65089 & 1.00037 & 1.00449 \\
\hline 0.4 & & & & & & & & & -0.56799 & -0.51801 & 1.30555 & 1.30923 \\
\hline & 0.2 & & & & & & & & -0.69823 & -0.65089 & 1.00037 & 1.00449 \\
\hline & 0.3 & & & & & & & & -0.66309 & -0.61813 & 1.00247 & 1.00667 \\
\hline & 0.4 & & & & & & & & -0.63657 & -0.59338 & 1.00398 & 1.00823 \\
\hline & & 0.2 & & & & & & & -0.69823 & -0.65089 & 1.00037 & 1.00449 \\
\hline & & 0.3 & & & & & & & -0.70488 & -0.65698 & 0.99967 & 1.00378 \\
\hline & & 0.4 & & & & & & & -0.71104 & -0.66262 & 0.99901 & 1.00319 \\
\hline & & & 0.1 & & & & & & -0.70645 & -0.65862 & 1.00702 & 1.01065 \\
\hline & & & 0.4 & & & & & & -0.68242 & -0.63604 & 0.98764 & 0.99267 \\
\hline & & & 0.7 & & & & & & -0.66018 & -0.61517 & 0.96983 & 0.97605 \\
\hline & & & & 0.1 & & & & & -0.61076 & -0.57139 & 1.01015 & 1.01426 \\
\hline & & & & 0.4 & & & & & -0.70930 & -0.66086 & 0.99866 & 1.00277 \\
\hline & & & & 0.7 & & & & & -0.72279 & -0.67289 & 0.99561 & 0.99972 \\
\hline & & & & & 0.1 & & & & -0.72206 & -0.67254 & 0.99836 & 1.00247 \\
\hline & & & & & 0.3 & & & & -0.67503 & -0.62976 & 1.00225 & 1.00636 \\
\hline & & & & & 0.5 & & & & -0.63026 & -0.58892 & 1.00564 & 1.00976 \\
\hline & & & & & & 0.5 & & & -0.69823 & -0.65089 & 1.00037 & 1.00449 \\
\hline & & & & & & 1.0 & & & -0.65672 & -0.60925 & 1.27971 & 1.28331 \\
\hline & & & & & & 1.5 & & & -0.62449 & -0.57729 & 1.54827 & 1.55136 \\
\hline & & & & & & & 0.5 & & -0.69823 & -0.65089 & 1.00037 & 1.00448 \\
\hline & & & & & & & 1.0 & & -0.88353 & -0.82394 & 0.98798 & 0.99236 \\
\hline & & & & & & & 1.5 & & -1.05121 & -0.98006 & 0.97645 & 0.98112 \\
\hline & & & & & & & & 0.5 & -0.698230 & -0.650892 & 1.000374 & 1.004489 \\
\hline & & & & & & & & 10 & -088353 & -082394 & 098798 & 0.99235 \\
\hline
\end{tabular}

Table 3: Concentration gradient for different values of pertinent parameters for the Sakiadis fluid flow case.

\begin{tabular}{|c|c|c|c|c|c|c|c|c|c|c|}
\hline \multirow{2}{*}{$B i_{1}$} & \multirow{2}{*}{$B i_{2}$} & \multirow{2}{*}{$K \boldsymbol{r}$} & \multirow{2}{*}{ Ec } & \multirow{2}{*}{$N b$} & \multirow{2}{*}{$N t$} & \multirow{2}{*}{$N r$} & \multirow{2}{*}{$M$} & \multirow{2}{*}{$\boldsymbol{K}$} & \multicolumn{2}{|c|}{$R e_{x}^{\frac{-1}{2}} S h$} \\
\hline & & & & & & & & & $E=0, \varepsilon=0$ & $E=0.2, \varepsilon=0.2$ \\
\hline 0.2 & & & & & & & & & 0.119470 & 0.119692 \\
\hline 0.3 & & & & & & & & & 0.117774 & 0.118270 \\
\hline 0.4 & & & & & & & & & 0.116168 & 0.116919 \\
\hline & 0.2 & & & & & & & & 0.117774 & 0.118270 \\
\hline & 0.3 & & & & & & & & 0.153265 & 0.153924 \\
\hline & 0.4 & & & & & & & & 0.180697 & 0.181486 \\
\hline & & 0.2 & & & & & & & 0.117774 & 0.118270 \\
\hline & & 0.3 & & & & & & & 0.120004 & 0.120478 \\
\hline & & 0.4 & & & & & & & 0.122075 & 0.122529 \\
\hline & & & 0.1 & & & & & & 0.117848 & 0.118332 \\
\hline
\end{tabular}




\begin{tabular}{|c|c|c|c|c|c|c|c|c|c|c|}
\hline \multirow{2}{*}{$B i_{1}$} & \multirow{2}{*}{$B i_{2}$} & \multirow{2}{*}{$K r$} & \multirow{2}{*}{$E c$} & \multirow{2}{*}{$N b$} & \multirow{2}{*}{$N t$} & \multirow{2}{*}{$N r$} & \multirow{2}{*}{$M$} & \multirow{2}{*}{$\boldsymbol{K}$} & \multicolumn{2}{|c|}{$R e_{x}^{\frac{-1}{2}} S h$} \\
\hline & & & & & & & & & $E=\mathbf{0}, \varepsilon=\mathbf{0}$ & $E=0.2, \varepsilon=0.2$ \\
\hline & & & 0.4 & & & & & & 0.117629 & 0.118147 \\
\hline & & & 0.7 & & & & & & 0.117417 & 0.117967 \\
\hline & & & & 0.1 & & & & & 0.087648 & 0.088747 \\
\hline & & & & 0.4 & & & & & 0.121727 & 0.122140 \\
\hline & & & & 0.7 & & & & & 0.126904 & 0.127209 \\
\hline & & & & & 0.1 & & & & 0.125621 & 0.125950 \\
\hline & & & & & 0.3 & & & & 0.110126 & 0.110780 \\
\hline & & & & & 0.5 & & & & 0.095348 & 0.096304 \\
\hline & & & & & & 0.5 & & & 0.117774 & 0.118270 \\
\hline & & & & & & 1.0 & & & 0.121814 & 0.122214 \\
\hline & & & & & & 1.5 & & & 0.124677 & 0.125014 \\
\hline & & & & & & & 0.5 & & 0.117774 & 0.118270 \\
\hline & & & & & & & 1.0 & & 0.113652 & 0.114201 \\
\hline & & & & & & & 1.5 & & 0.109710 & 0.110311 \\
\hline & & & & & & & & 0.5 & 0.117774 & 0.118270 \\
\hline & & & & & & & & 1.0 & 0.113652 & 0.114201 \\
\hline & & & & & & & & 1.5 & 0.109710 & 0.110311 \\
\hline
\end{tabular}

Table 4: Skin friction coefficient, wall temperature gradient for different values of pertinent parameters for Blasius fluid flow case.

\begin{tabular}{|c|c|c|c|c|c|c|c|c|c|c|c|c|}
\hline \multirow{2}{*}{$B i_{1}$} & \multirow{2}{*}{$B i_{2}$} & \multirow{2}{*}{$K r$} & \multirow{2}{*}{$E c$} & \multirow{2}{*}{$N b$} & \multirow{2}{*}{$N t$} & \multirow{2}{*}{$N r$} & \multirow{2}{*}{$M$} & \multirow{2}{*}{$K$} & \multicolumn{2}{|c|}{$R e_{x}^{\frac{1}{2}} C f$} & \multicolumn{2}{|c|}{$R e_{x}^{\frac{-1}{2}} N u$} \\
\hline & & & & & & & & & $E=0, \varepsilon=0$ & $\begin{array}{l}E=0.2 \\
\varepsilon=0.2\end{array}$ & $E=0, \varepsilon=0$ & $\begin{array}{l}E=0.2, \\
\varepsilon=0.2\end{array}$ \\
\hline 0.2 & & & & & & & & & 0.80239 & 0.76805 & 0.57101 & 0.57356 \\
\hline 0.3 & & & & & & & & & 1.01902 & 0.95355 & 0.93912 & 0.9431 \\
\hline \multirow[t]{25}{*}{0.4} & & & & & & & & & 1.16541 & 1.07361 & 1.20188 & 1.20533 \\
\hline & 0.2 & & & & & & & & 1.01902 & 0.95355 & 0.93913 & 0.94306 \\
\hline & 0.3 & & & & & & & & 1.06067 & 0.99233 & 0.94001 & 0.94430 \\
\hline & 0.4 & & & & & & & & 1.09015 & 1.01978 & 0.94057 & 0.94513 \\
\hline & & 0.2 & & & & & & & 1.01902 & 0.95355 & 0.93913 & 0.94306 \\
\hline & & 0.3 & & & & & & & 1.00809 & 0.94353 & 0.93858 & 0.94244 \\
\hline & & 0.4 & & & & & & & 0.99794 & 0.93423 & 0.93806 & 0.94185 \\
\hline & & & 0.1 & & & & & & 1.00776 & 0.94479 & 0.94853 & 0.95177 \\
\hline & & & 0.4 & & & & & & 1.04284 & 0.97196 & 0.91921 & 0.92466 \\
\hline & & & 0.7 & & & & & & 1.08234 & 1.00206 & 0.88611 & 0.89428 \\
\hline & & & & 0.1 & & & & & 1.11521 & 1.04031 & 0.94554 & 0.9501 \\
\hline & & & & 0.4 & & & & & 1.00724 & 0.94288 & 0.93770 & 0.9415 \\
\hline & & & & 0.7 & & & & & 0.99340 & 0.93024 & 0.93465 & 0.93842 \\
\hline & & & & & 0.1 & & & & 0.99313 & 0.93027 & 0.93832 & 0.94209 \\
\hline & & & & & 0.3 & & & & 1.04440 & 0.97636 & 0.93983 & 0.9439 \\
\hline & & & & & 0.5 & & & & 1.09382 & 1.02070 & 0.94098 & 0.94545 \\
\hline & & & & & & 0.5 & & & 1.01902 & 0.95355 & 0.93912 & 0.94307 \\
\hline & & & & & & 1.0 & & & 1.05443 & 0.98169 & 1.20631 & 1.20994 \\
\hline & & & & & & 1.5 & & & 1.08163 & 1.00327 & 1.46503 & 1.46838 \\
\hline & & & & & & & 0.5 & & 1.01902 & 0.95355 & 0.93913 & 0.9430 \\
\hline & & & & & & & 1.0 & & 0.95954 & 0.89685 & 0.93160 & 0.9353 \\
\hline & & & & & & & 1.5 & & 0.91238 & 0.85193 & 0.92539 & 0.92892 \\
\hline & & & & & & & & 0.5 & 1.01902 & 0.95355 & 0.93912 & 0.94306 \\
\hline & & & & & & & & 1.0 & 0.959541 & 0.89683 & 0.93160 & 0.93532 \\
\hline & & & & & & & & 1.5 & 0.91238 & 0.851938 & 0.925397 & 0.92892 \\
\hline
\end{tabular}


Table 5. Concentration gradient for different values of pertinent parameters for the Blasius fluid flow case.

\begin{tabular}{|c|c|c|c|c|c|c|c|c|c|c|}
\hline \multirow{2}{*}{$B i_{1}$} & \multirow{2}{*}{$B i_{2}$} & \multirow{2}{*}{$K r$} & \multirow{2}{*}{$E c$} & \multirow{2}{*}{$N b$} & \multirow{2}{*}{$N t$} & \multirow{2}{*}{$\mathrm{Nr}$} & \multirow{2}{*}{$M$} & \multirow{2}{*}{$\boldsymbol{K}$} & \multicolumn{2}{|c|}{$R e_{x}^{\frac{-1}{2}} S h$} \\
\hline & & & & & & & & & $E=\mathbf{0}, \varepsilon=\mathbf{0}$ & $E=0.2, \varepsilon=0.2$ \\
\hline 0.2 & & & & & & & & & 0.094846 & 0.095240 \\
\hline 0.3 & & & & & & & & & 0.097489 & 0.098331 \\
\hline \multirow[t]{25}{*}{0.4} & & & & & & & & & 0.098172 & 0.099371 \\
\hline & 0.2 & & & & & & & & 0.097489 & 0.098331 \\
\hline & 0.3 & & & & & & & & 0.122747 & 0.123825 \\
\hline & 0.4 & & & & & & & & 0.141332 & 0.142585 \\
\hline & & 0.2 & & & & & & & 0.097489 & 0.098331 \\
\hline & & 0.3 & & & & & & & 0.100793 & 0.101595 \\
\hline & & 0.4 & & & & & & & 0.103861 & 0.104625 \\
\hline & & & 0.1 & & & & & & 0.097378 & 0.098214 \\
\hline & & & 0.4 & & & & & & 0.097700 & 0.098557 \\
\hline & & & 0.7 & & & & & & 0.097982 & 0.098875 \\
\hline & & & & 0.1 & & & & & 0.068305 & 0.070075 \\
\hline & & & & 0.4 & & & & & 0.101274 & 0.101998 \\
\hline & & & & 0.7 & & & & & 0.106253 & 0.106824 \\
\hline & & & & & 0.1 & & & & 0.104881 & 0.105488 \\
\hline & & & & & 0.3 & & & & 0.090238 & 0.091312 \\
\hline & & & & & 0.5 & & & & 0.076111 & 0.077652 \\
\hline & & & & & & 0.5 & & & 0.097489 & 0.098331 \\
\hline & & & & & & 1.0 & & & 0.102232 & 0.102893 \\
\hline & & & & & & 1.5 & & & 0.105578 & 0.106124 \\
\hline & & & & & & & 0.5 & & 0.097489 & 0.098331 \\
\hline & & & & & & & 1.0 & & 0.090727 & 0.091646 \\
\hline & & & & & & & 1.5 & & 0.084447 & 0.085433 \\
\hline & & & & & & & & 0.5 & 0.097489 & 0.098331 \\
\hline & & & & & & & & 1.0 & 0.090727 & 0.091646 \\
\hline & & & & & & & & 1.5 & 0.084447 & 0.085433 \\
\hline
\end{tabular}

\section{Conclusions}

In this investigation, we presented the influences of various governing physical parameters on fluid velocity, temperature, and concentration distributions. The presented analysis also elaborates the features of variable thermal conductivity, the viscous dissipation and chemical reaction being taken into account. Based on the present investigation the following observations are made: The rate of mass transfer is higher in Blasius flow compared with Sakiadis flow case; The Eckert number increases the friction factor coefficient for both Blasius and Sakiadis fluid flow cases; The porosity parameter decelerates the friction factor coefficient; The thermophoresis parameter enhances the heat transfer rates in both Blasius and Sakiadis fluid cases.

\section{Funding}

This research received no external funding.

\section{Acknowledgments}

The authors would like to thank the anonymous reviewers for their valuable comments and suggestions to improve the quality of the paper. 


\section{Conflicts of Interest}

\section{The authors declare no conflict of interest.}

\section{References}

1. Blasius, H. Grenzschichten in Flussigkeiten mit kleiner Reibung. Z Math Physik, 1908, 56,1-37. https://ntrs.nasa.gov/search.jsp?R=20050028493 2020-07-15T05:51:47+00:00Z.

2. Sakiadis, B.C. Boundary-layer behavior on continuous solid surfaces: II. The boundary layer on a continuous flat surface. AICHE J. 1961, 7, 221-225, https://doi.org/10.1002/aic.690070211.

3. Pop, H.; Watanabe, W. The effects of suction or injection in boundary layer flow and heat transfer on a continuous moving surface. Technische Mechanik, 1992, 13, 49-54.

4. Krishna, C.M.; ViswanathaReddy, G.; Souayeh, B.; Raju, C.S.K.; Rahimi-Gorji, M.; Raju, S.S.K. Thermal convection of MHD Blasius and Sakiadis flow with thermal convective conditions and variable properties. Microsystem Technologies 2019, 25, 3735-3746, https://doi.org/10.1007/s00542-019-04353-y.

5. Mabood, F.; Khan, W.A. A computational study of unsteady radiative magnetohydrodynamic Blasius and Sakiadis flow with leading-edge accretion (ablation). Heat Transfer 2020, 49, 1355-1373, https://doi.org/10.1002/htj.21666.

6. Ganesh, N.V.; Al-Mdallal, Q.M.; Reena, K.; Aman, S. Blasius and Sakiadis slip flow of H2O-C2H6O2 (50:50) based nanoliquid with different geometry of boehmite alumina nanoparticles. Case Studies in Thermal Engineering 2019, 16, 100546, https://doi.org/10.1016/j.csite.2019.100546.

7. Krishna, C.M.; Reddy, G.V.; Raju, C.S.K. Thermal and Diffusion Slips on Natural Convection of MHD Blasius and Sakiadis Flows with Variable Properties and Non-Uniform Heat Source or Sink. Journal of Nanofluids 2019, 8, 683-693, https://doi.org/10.1166/jon.2019.1641.

8. Xu, H. Homogeneous-Heterogeneous Reactions of Blasius Flow in a Nanofluid. J. Heat Transfer 2018, 141, https://doi.org/10.1115/1.4041801.

9. Afridi, M.I.; Qasim, M. Second law analysis of Blasius flow with nonlinear Rosseland thermal radiation in the presence of viscous dissipation. Propulsion and Power Research 2019, 8, 234-242, https://doi.org/10.1016/j.jppr.2018.06.001.

10. Shateyi, S.; Muzara, H. Unsteady MHD Blasius and Sakiadis flows with variable thermal conductivity in the presence of thermal radiation and viscous dissipation. Frontiers in Heat and Mass Transfer (FHMT) 2020, 14, http://dx.doi.org/10.5098/hmt.14.18.

11. Mukhopadhyay, S. Unsteady boundary layer flow and heat transfer past a porous stretching sheet in presence of variable viscosity and thermal diffusivity. Int. J. Heat Mass Transfer 2009, 52, 5213-5217, https://doi.org/10.1016/j.ijheatmasstransfer.2009.04.013.

12. Grubka, L.J.; Bobba, K.M. Heat Transfer Characteristics of a Continuous, Stretching Surface With Variable Temperature. J. Heat Transfer 1985, 107, 248-250, https://doi.org/10.1115/1.3247387.

13. Ali, M.E. Heat transfer characteristics of a continuous stretching surface. Wärme - und Stoffübertragung 1994, 29, 227-234, https://doi.org/10.1007/BF01539754.

14. Ishak, A.; Nazar, R.; Pop, I. Flow and heat transfer characteristics on a moving flat plate in a parallel stream with constant surface heat flux. Heat Mass Transfer. 2009, 45, 563-567, https://doi.org/10.1007/s00231-0080462-9.

15. Khan, S.I.; Khan, U.; Ahmed, N.; Jan, S.U.; Waheed, A.; Mohyud-Din, S.T. Effects of Viscous Dissipation and Convective Boundary Conditions on Blasius and Sakiadis Problems for Casson Fluid. Natl. Acad. Sci. Lett. 2015, 38, 247-250, https://doi.org/10.1007/s40009-014-0331-7.

16. Sajid, M.U.; Ali, H.M.; Sufyan, A.; Rashid, D.; Zahid, S.U.; Rehman, W.U. Experimental investigation of TiO2-water nanofluid flow and heat transfer inside wavy mini-channel heat sinks. J. Therm. Anal. Calorim. 2019, 137, 1279-1294, https://doi.org/10.1007/s10973-019-08043-9.

17. Upadhya, S.M.; Devi, R.L.V.R.; Raju, C.S.K.; Ali, H.M. Magnetohydrodynamic nonlinear thermal convection nanofluid flow over a radiated porous rotating disk with internal heating. J. Therm. Anal. Calorim. 2020, https://doi.org/10.1007/s10973-020-09669-w.

18. Arzani, H.; Adabi, M.; Mosafer, J.;Dorkoosh, F.; Khosravani, M.; Maleki, H.; Nekounam, H; Kamali, M.; 2019. Preparation of curcumin-loaded PLGA nanoparticles and investigation of its cytotoxicity effects on human glioblastoma U87MG cells. Biointerface Research in Applied Chemistry 2019, 9, 4225-4231. https://doi.org/10.33263/BRIAC/95.225231.

19. Shojaee, A.; Mostafavi, A.; Shamspur, T; Fathirad, F. Biointerface Green synthesis of cerium oxide nanoparticles: characterization, parameters optimization and investigation of photocatalytic application. Biointerface Research in Applied Chemistry 2020, 10,5932-5937, https://doi.org/10.33263/BRIAC104.932937.

20. Suhartono, S; Syafiuddin, A.A proposed activated carbon for the removal of silver nanoparticles from water Environment. Biointerface Research in Applied Chemistry 2020, 10, 5478-5483. https://doi.org/10.33263/BRIAC103.478483. 
21. Upadhya, S.M.; Raju, S.S.K.; Raju, C.S.K.; Mnasri, C. Arrhenius Activation and Zero Mass Flux Conditions on Nonlinear Convective Jeffrey Fluid over an Electrically Conducting and Radiated Sheet. Arabian Journal for Science and Engineering 2020, https://doi.org/10.1007/s13369-020-04687-0.

22. Sheikholeslami, M.; Domiri Ganji, D.; Younus Javed, M.; Ellahi, R. Effect of thermal radiation on magnetohydrodynamics nanofluid flow and heat transfer by means of two phase model. J. Magn. Magn. Mater. 2015, 374, 36-43, https://doi.org/10.1016/j.jmmm.2014.08.021.

23. Rashid, M.; Khan, M.I.; Hayat, T.; Khan, M.I.; Alsaedi, A. Entropy generation in flow of ferromagnetic liquid with nonlinear radiation and slip condition. J. Mol. Liq. 2019, 276, 441-452, https://doi.org/10.1016/j.molliq.2018.11.148.

24. Pal, D.; Chatterjee, D.; Vajravelu, K. Influence of magneto-thermo radiation on heat transfer of a thin nanofluid film with non-uniform heat source/sink. Propulsion and Power Research 2020, 9, 169-180, https://doi.org/10.1016/j.jppr.2020.03.003.

25. Li, X.; Tu, J. Evaluation of the eddy viscosity turbulence models for the simulation of convection-radiation coupled heat transfer in indoor environment. Energy and Buildings 2019, 184, 8-18, https://doi.org/10.1016/j.enbuild.2018.11.043. 